\title{
Aponuphis Kucheruk, 1978 (Annelida: Onuphidae) from western African waters
}

\author{
P.B. Borisova', D.M. Schepetov², N.E. Budaeva ${ }^{3,4}$ \\ ${ }^{1}$ Biological Faculty, Moscow State University, Leninskiye Gory 1-12, Moscow 119234 Russia. E- \\ mail:salixhastata@yandex.ru \\ ${ }^{2}$ Koltzov Institute of Developmental Biology Russian Academy of Sciences, 26 Vavilov Str., Moscow \\ 119334 Russia. \\ ${ }^{3}$ Department of Natural History, University Museum of Bergen, University of Bergen, Allégaten 41, \\ 5007 Bergen, Norway.E-mail: nataliya.budaeva@uib.no \\ ${ }^{4}$ P.P. Shirshov Institute of Oceanology, Russian Academy of Sciences, Nakhimovsky pr. 36, Moscow \\ 117997 Russia.
}

ABSTRACT: Ninety-one specimens of Aponuphis from 27 stations off the western African coast from Morocco to Angola as well as from two localities in the North Sea and from a single locality off Mallorca in the Mediterranean Sea were examined using light and scanning electron microscopy. A fragment of 16 rDNA was obtained for 29 specimens of Aponuphis. A Neighbor Joining analysis revealed the presence of two species complexes (A. bilineata species complex and A. brementi species complex), A. ornata and a potentially new species Aponuphis sp. Besides three typical color morphs characteristic to A. bilineata, $A$. brementi, and A. ornata, the large number of specimens displayed indistinct color patterns of transversal pigmented bands or dots on anterior chaetigers. Specimens with such coloration were found in A. bilineata, A. brementi and the new species Aponuphis sp. Only $A$. ornata showed constant "horse-shoe" color pattern.

How to cite this article: Borisova P.B., Schepetov D.M., Budaeva N.E. 2018. Aponuphis Kucheruk, 1978 (Annelida: Onuphidae) from western African waters // Invert. Zool. Vol.15. No.1. P.19-41. doi: 10.15298/invertzool.15.1.02

KEY WORDS: Onuphinae, fauna, East Atlantic, morphology, molecular analysis, 16S rDNA, color polymorphism.

\section{Многощетинковые черви рода Aponuphis Kucheruk, 1978 (Annelida: Onuphidae) из вод Западной Африки}

П.Б. Борисова ${ }^{1}$, Д.М. Щепетов ${ }^{2}$, Н.Е. Будаева ${ }^{3,4}$

\footnotetext{
${ }^{1}$ Биологический факультет, Московский государственный университет им. М.В. Ломоносова, Ленинские горы 1-12, Москва 119234 Россия. E-mail: salixhastata@yandex.ru

${ }^{2}$ Институт биологии развития им. Н.К. Кольцова Российской академии наук, ул. Вавилова, 26, Москва 119334 Россия.

${ }^{3}$ Department of Natural History, University Museum of Bergen, University of Bergen, Allégaten 41, 5007 Bergen, Norway. E-mail: nataliya.budaeva@uib.no

${ }^{4}$ Институт океанологии им. П.П. Ширшова Российской академии наук, Нахимовский проспект, 36, Москва 117997 Россия.
}

РЕЗЮМЕ: Девяносто один экземпляр из рода Aponuphis, собранный на 27 станциях из восточной Атлантики, преимущественно с шельфа Западной Африки от Марокко 
до Анголы, а также из Северного и Средиземного морей, был исследован методами световой и сканирующей электронной микроскопии. Получены последовательности участка гена 16S рДНК для 29 экземпляров из рода Aponuphis. На основе анализа последовательностей методом ближайшего соседа в исследованном материале обнаружены два видовых комплекса (комплекс видов A. bilineata и комплекс видов $A$. brementi), а также вид A. ornata и потенциально новый для науки вид Aponuphis sp. Анализ соответствия цветовых морф генетическим видам показал, что, наряду с тремя типовыми морфами, характерными для трех вышеперечисленных видов, имеется большое число экземпляров с неявной окраской в виде тонких поперечных дорзальных полосок или точек. Данные экземпляры встречаются как у нового, ранее неизвестного вида Aponuphis sp., так и в рамках видовых комплексов A. bilineata и A. brementi. Исключение составил A. ornata с характерным подковообразным рисунком на передних сегментах, все исследованные экземпляры которого обладали схожим паттерном.

Как цитировать эту статью: Borisova P.B., Schepetov D.M., Budaeva N.E. 2018. Aponuphis Kucheruk, 1978 (Annelida: Onuphidae) from western African waters // Invert. Zool. Vol.15. No.1. P.19-41. doi: 10.15298/invertzool.15.1.02

КЛЮЧЕВЫЕ СЛОВА: Onuphinae, фауна, восточная Атлантика, морфология, молекулярно-генетический анализ, 16S рДНК, цветовой полиморфизм.

\section{Introduction}

Aponuphis Kucheruk, 1978 has been described for Onuphis-like worms lacking peristomial cirri (Kucheruk, 1978). Aponuphis and Onuphis Audouin et Milne Edwards, 1833 are morphologically very similar genera sharing the presence of long multiringed palpophores exceeding in length the palpostyles. In both genera, the anterior three to seven pairs of parapodia are modified but not enlarged and bear bi- to tridentate (rarely quadridentate) pseudocompound falcigers with short pointed hoods. Simple strap-like branchiae, if present, start in the anterior part of the body and continue throughout the whole length of a worm.

In her generic revision of Onuphidae, Paxton (1986) assigned six species previously described as Hyalinoecia Malmgren, 1867 or Onuphis to Aponuphis. Hyalinoecia also lacks peristomial cirri and this character was considered to have high diagnostic value in early onuphid studies. Paxton (1986) has demonstrated that Hyalinoecia and Aponuphis belong to two different subfamilies: Hyalinoeciinae Paxton, 1986 and Onuphinae Kinberg, 1865 respectively. After Paxton's revision, two abran- chiate species, Aponuphis chistikovi Detinova, 1985 from the Reykjanes Ridge in the northern Mid-Atlantic and A. willsiei Cantone et Bellan, 1996 from the Gulf of Marseille, Mediterranean were described. Recently, three new species have been described from eastern Australia (Paxton, 2017), bringing the total number of species in the genus to ten and expanding the geographical range of the genus to southern Pacific (Table 1).

Aponuphis has been previously reported from African waters (Fauvel, 1936; Rullier, 1965). Intes and Le Loeuff(1975) reported A. bilineata (Baird, 1870) from Senegal and Ivory Coast at depths around $100 \mathrm{~m}$ and $A$. fauveli (Rioja, 1918) from Senegal and Togo at depths between 25 and $200 \mathrm{~m}$. Kirkegaard (1988) reported Aponuphis along the western African coast from Morocco to Gabon. He followed Bellan (1964) in combining all described species of Aponuphis into a single species, $A$. bilineata, with high intraspecific variation. However, he made an exception for $A$. fauveli based on the appearance of the branchiae on the first chaetiger and considered it as a valid species. Kirkegaard (1988) also reported a subspecies of $A$. fauveli, A. fauveli africana (Rullier, 1965), with the 


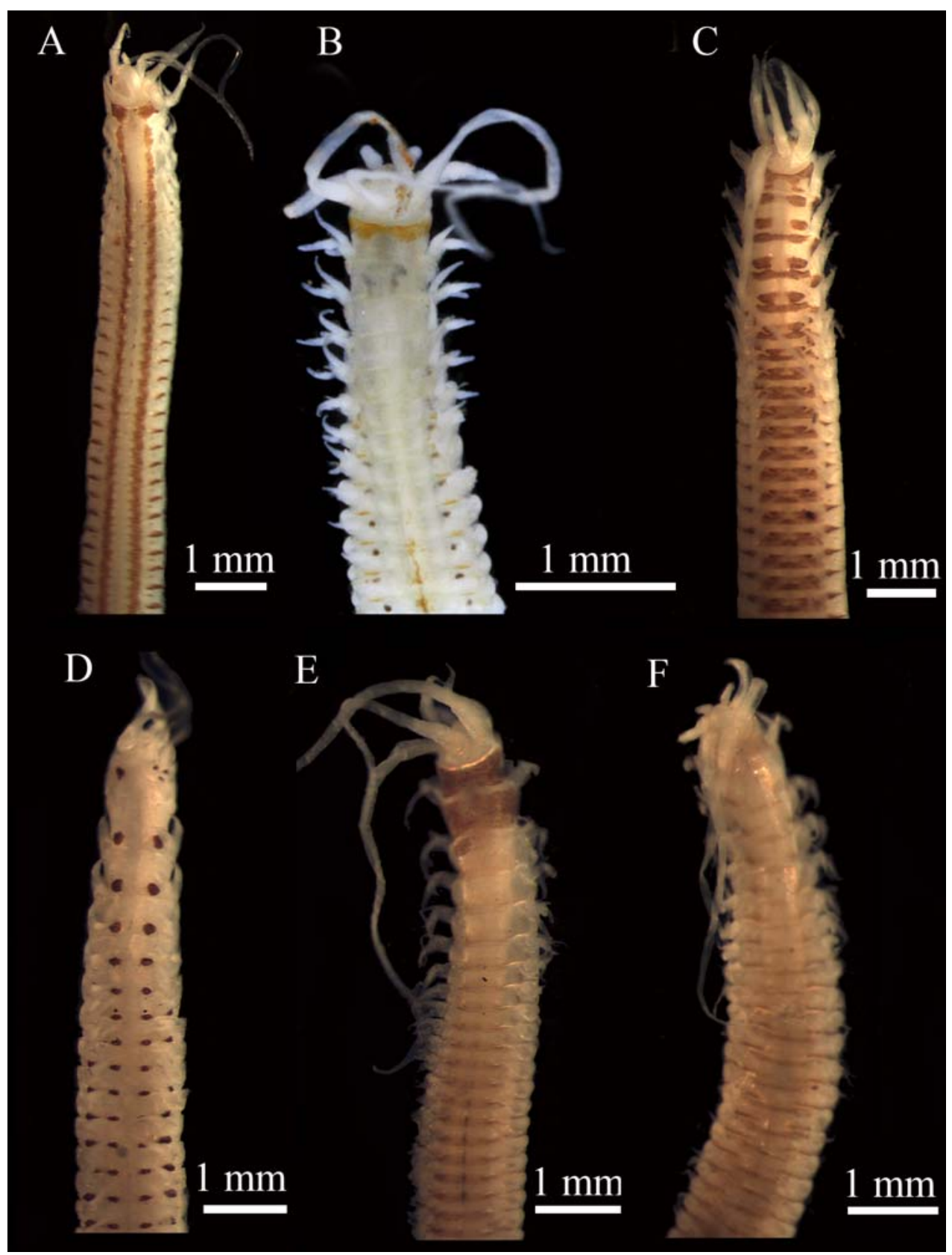

Fig. 1. Various color morphs in Aponuphis. A, B - A. bilineata; C - A. ornata; D-F - A. brementi. Рис. 1. Цветовые морфы в роде Aponuphis. А, В - A. bilineata; C - A. ornata; D-F - A. brementi.

distinct color pattern of two pigmented anterior segments with following $8-10$ chaetigers bearing lunular rusty spots.

Recently Arias and Paxton (2015) have revised the fauna of Onuphis and Aponuphis from southwestern Europe based on type and large non-type material of all valid species. They suggested synonymization of Aponuphis rubra (Langerhans, 1880) with $A$. bilineata and $A$. fauveli with $A$. brementi (Fauvel, 1916). Sever- 
al color morphs were reported in species with branchiae. A bilineata displayed two color morphs with typical pattern of two longitudinal dorsal stripes along the whole body (Figs 1A, $2 \mathrm{~A}$ ) and an additional much darker morph with the anterior part of the body almost completely pigmented. A. brementi bore a pair of dark dorsal round spots on each segment (Figs 1D, 2D), while A. ornata (Fauvel, 1928) had a typical "horse-shoe" pattern formed by a band and two large square spots on adjacent chaetigers (Figs 1C, 2C). The abranchiate $A$. willsiei lacked a color pattern. Arias and Paxton (2015) suggest that color morphs can be used in species identification in Aponuphis, however this character should be used with caution since some specimens may lose coloration in preserved condition.

Very little genetic data are known for Aponuphis. A single specimen of Aponuphis bilineata was used in a phylogenetic analysis of Eunicida (Struck et al., 2006). Two more species were included in the analysis of phylogenetic relationships within Onuphidae, where Aponuphis was shown to be monophyletic and sister to Onuphis (Budaeva et al., 2016). However, the analysis included only few representatives of both genera and larger taxon sampling is required to confirm their phylogenetic status.

Both Onuphis and Aponuphis are tubicolous sediment dwellers constructing cylindrical tubes with inner mucous or parchment-like layer covered with mud or sand particles, rarely tough and smooth, lacking any foreign particles (Paxton, 2017). Unlike species-rich Onuphis with world-wide distribution, Aponuphis is a relatively small genus comprising ten species reported only from the North Atlantic and eastern Australia (Paxton, 1986, 2017; Arias, Paxton, 2015) (Table 1).

The goal of the present study is to examine material of Aponuphis from the western African waters combining morphological and molecular methods. We aim to assess the correspondence of the color morphs with the morphological and genetic species in Aponuphis and to clarify their distribution in the eastern Atlantic.

\section{Materials and Methods}

\section{Study area}

Material used in the present study was borrowed from the collection of the University Museum of Bergen. The samples were collected during two projects: Canary Current Large Marine Ecosystem (CCLME) project and Guinea Current Large Marine Ecosystem (GCLME) project. Ninety-one specimens from 27 stations were collected between 2005 and 2012 along the western African coast from Morocco to Angola using a grab or a sledge (Appendix 1). The sampled depth range was from 7 to $518 \mathrm{~m}$ however most of the samples were obtained at depths around $60-100 \mathrm{~m}$. In addition, the specimens from two stations from the North Sea and from a single locality off Mallorca in the Mediterranean Sea were examined. Panmap (Diepenbroek et al., 2000) was used to build the distribution maps of the studied species.

\section{Morphology}

Part of the material was fixed in $4 \%$ formalin and later transferred into $75 \%$ ethanol. Specimens used for DNA analysis were fixed in $96 \%$ ethanol. Morphology of the specimens was studied using light and scanning electron microscopy. Identification of different morphotypes was done using a Leica MZ16 dissecting microscope. Slides of parapodia and chaetae were photographed using a Leica DM6000 B light microscope. For scanning electron microscopy, specimens were dehydrated in a graded ethanol series, critical-point dried, sputter coated with gold and examined with a ZEISS Supra 55VP scanning electron microscope and a Camscan S2 scanning electron microscope. All materials are deposited in the University museum of Bergen (ZMBN).

\section{Molecular methods}

We have sampled 29 specimens of Aponuphis representing six different color morphs. In 
A

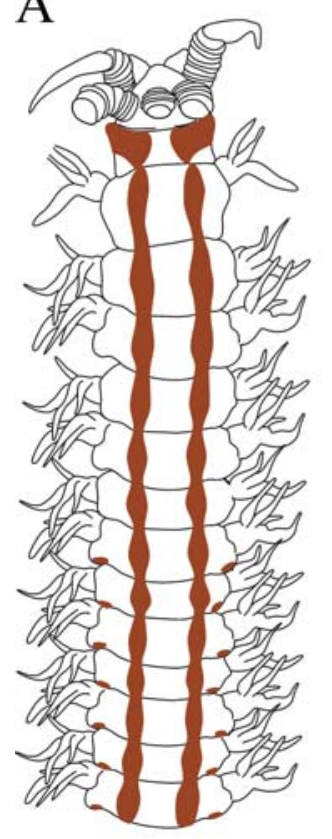

$\mathrm{D}$

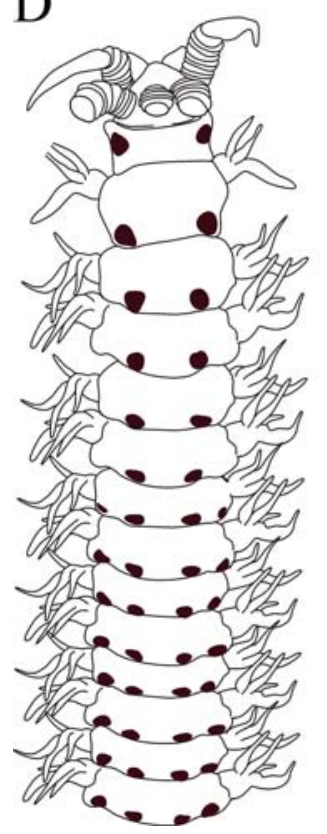

B

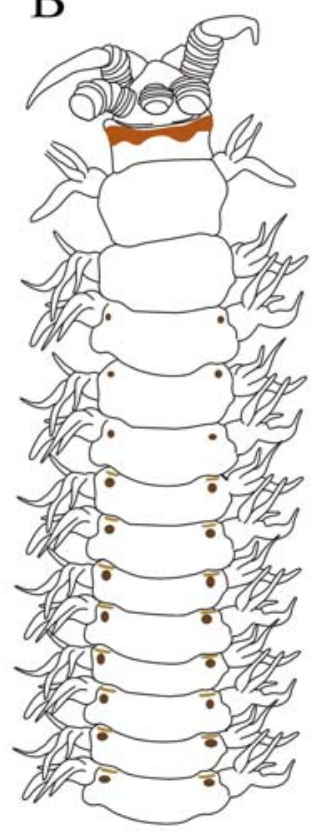

$\mathrm{E}$

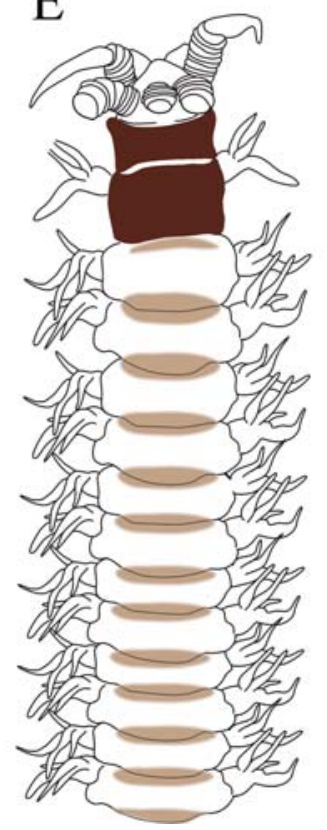

$\mathrm{C}$

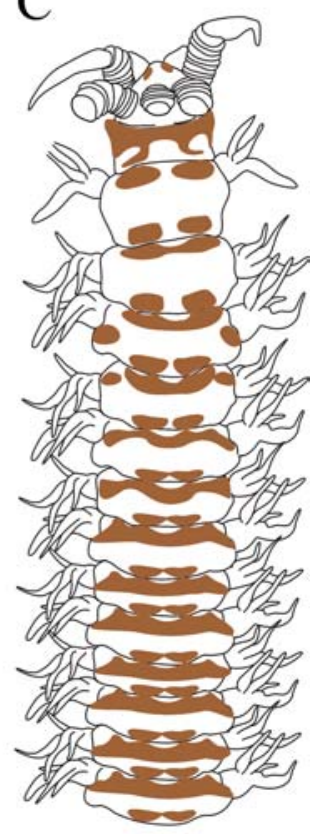

$\mathrm{F}$

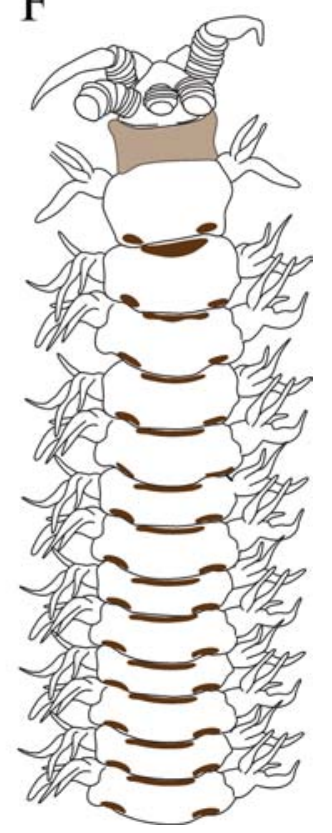

Fig. 2. Schematic interpretation of various color morphs in Aponuphis. A, B - A. bilineata; $\mathrm{C}-$ A. ornata; $\mathrm{D}-\mathrm{F}-A$. brementi.

Рис. 2. Схематическое изображение цветовых морф в роде Aponuphis. А, В - A. bilineata; $\mathrm{C}-A$. ornata; D-F - A. brementi. 
Table 1. Valid species of Aponuphis and their synomyms. Таблица 1. Валидные виды рода Aponuphis и их синонимы.

\begin{tabular}{|l|l|}
\hline Species & Synonymised names \\
\hline Aponuphis annae Paxton, 2017 & \\
\hline Aponuphis bellani Paxton, 2017 & \\
\hline Aponuphis bilineata (Baird, 1870) & Aponuphis rubra (Langerhans, 1880) \\
\hline Aponuphis brementi (Fauvel, 1916) & Aponuphis fauveli (Rioja, 1918) \\
\hline Aponuphis chistikovi Detinova, 1985 & \\
\hline Aponuphis danicae Paxton, 2017 & \\
\hline Aponuphis grubii (Marenzeller, 1886) & $\begin{array}{l}\text { Aponuphis bilineata grubii } \\
\text { (Marenzeller, 1886) }\end{array}$ \\
\hline Aponuphis ornata (Fauvel, 1928) & \\
\hline Aponuphis rigida (Claparède, 1868) & \\
\hline $\begin{array}{l}\text { Aponuphis willsiei Cantone et Bellan, } \\
\text { 1996 }\end{array}$ & Aponuphis willsii [auct.] \\
\hline
\end{tabular}

addition, three sequences of $16 \mathrm{~S}$ rDNA of $A$. fauveli, A. bilineata and Aponuphis sp. were retrieved from GenBank. Seven sequences representing four Onuphis species were included in the analysis to check the monophyletic status of both genera. Hyalinoecia tubicola (O.F. Müller, 1776) and Nothria conchylega (Sars, 1835) belonging to the sister subfamily Hyalinoeciinae were used as outgroups. Collection data and Genbank accession numbers of all specimens included in the molecular analysis are shown in Table 2.

Genomic DNA was extracted from 96\% ethanol fixed samples using silica gel (glass milk). A fragment of mitochondrial gene $16 \mathrm{~S}$ rDNA ( $\sim 400$ bp) was amplified using the following primers: forward 16Sarl CGCCTGTTTAACAAAAACAT (Palumbi et al., 1991) and reverse 16SR CCGRTYTGAACTCAGCTCACG (Puslednik, Serb, 2008). The total volume of PCR was $20 \mu$ l. PCR were performed using two commercial Evrogen ${ }^{\mathrm{TM}}$ kits following the instructions provided by the producer: Encyclo Plus PCR kit $(0.1 \mu 150 X$ Encyclo DNA Polymerase; $\mathrm{ddH}_{2} \mathrm{O} ; 4 \mu 15 \mathrm{X}$ Encyclo Red buff- er; $0.4 \mu 150 \mathrm{X}$ dNTP; $0.2-0.5 \mu \mathrm{l}(10 \mathrm{Pmol} / \mu \mathrm{l})$ of each primer) and Screen Mix 5X (4 $\mu 1$ Screen Mix 5X; dd $\mathrm{H}_{2} \mathrm{O} ; 0.2-0.5 \mu \mathrm{l}(10 \mathrm{Pmol} / \mu \mathrm{l})$ of each primer) with $1-2 \mu 1$ of DNA template. $\mathrm{PCR}$ thermal conditions were: 1 cycle: $95^{\circ} \mathrm{C} / 5 \mathrm{~min}$; 35-40 cycles: $95^{\circ} \mathrm{C} / 15 \mathrm{~s}, 50-52^{\circ} \mathrm{C} / 40 \mathrm{~s}, 72^{\circ} \mathrm{C} /$ $45 \mathrm{~s} ; 1$ cycle: $72^{\circ} \mathrm{C} / 2 \mathrm{~min}$. The results of PCR were verified using $1 \%$ agarose gel electrophoresis with ethidium bromide. Purification of the PCR products was done using Ethanol/ EDTA/Sodium Acetate Precipitation. Sequencing reactions for both strands of the amplified genes were performed using BigDye Terminator v3.1 Cycle Sequencing Kit (Applied Biosystems) using the same primers as for PCR. Products were sequenced using Applied Biosystems automated sequencer ABI 3500.

Sequence contigs were assembled in CodonCode Aligner v. 6.0. Alignment was conducted using the MUSCLE (Edgar, 2004) algorithm implemented in MEGA v. 7.0 (Kumar et al., 2016) with the following settings: -400 gap opening penalty, -50 gap extension penalty. We used Neighbor Joining algorithm implemented in MEGA v.5.1 to provide graphical interpreta- 
Table 2. List of species used in the phylogenetic analyses with description of color morphs, geographical localities and GenBank accession numbers.

Таблица 2. Список видов, использованных в молекулярном анализе, с указанием цветовой морфы, географического местонахождения и регистрационного номера ГенБанка для каждого экземпляра.

\begin{tabular}{|c|c|c|c|c|c|}
\hline Species & $\begin{array}{l}\text { Clade } \\
\text { code }\end{array}$ & Color pattern & $\begin{array}{l}\text { Catalo- } \\
\text { gue } \\
\text { number }\end{array}$ & Country & $\begin{array}{l}\text { GenBank } \\
\text { Accession } \\
\text { Number }\end{array}$ \\
\hline \multirow{12}{*}{ A. bilineata } & Clade A & $\begin{array}{l}\text { two longitudinal } \\
\text { stripes }\end{array}$ & $\begin{array}{l}\text { ZMBN } \\
91345\end{array}$ & $\begin{array}{l}\text { Morocco, } 29.0031^{\circ} \mathrm{N} \\
11.2162^{\circ} \mathrm{W}, 106 \mathrm{~m}\end{array}$ & KX874564 \\
\hline & Clade A & $\begin{array}{l}\text { two longitudinal } \\
\text { stripes }\end{array}$ & $\begin{array}{l}\text { ZMBN } \\
91346\end{array}$ & $\begin{array}{l}\text { Morocco, } 29,6089^{\circ} \mathrm{N} \\
10.2905^{\circ} \mathrm{W}, 102 \mathrm{~m}\end{array}$ & KX874565 \\
\hline & Clade A & $\begin{array}{l}\text { two longitudinal } \\
\text { stripes }\end{array}$ & $\begin{array}{l}\text { ZMBN } \\
91348\end{array}$ & $\begin{array}{l}\text { Morocco, } 32.5418^{\circ} \mathrm{N} \\
9.6138^{\circ} \mathrm{W}, 101 \mathrm{~m}\end{array}$ & KX874566 \\
\hline & Clade A & $\begin{array}{l}\text { two longitudinal } \\
\text { stripes }\end{array}$ & $\begin{array}{l}\text { ZMBN } \\
111713\end{array}$ & $\begin{array}{l}\text { W. Sahara, } 27.1015^{\circ} \mathrm{N} \\
13.672^{\circ} \mathrm{W}, 125 \mathrm{~m}\end{array}$ & KX874568 \\
\hline & Clade A & $\begin{array}{l}\text { two longitudinal } \\
\text { stripes }\end{array}$ & $\begin{array}{l}\text { ZMBN } \\
111714\end{array}$ & $\begin{array}{l}\text { Morocco, } 29.0031^{\circ} \mathrm{N} \\
11.2162^{\circ} \mathrm{W}, 106 \mathrm{~m}\end{array}$ & KX874562 \\
\hline & Clade A & $\begin{array}{l}\text { two longitudinal } \\
\text { stripes }\end{array}$ & $\begin{array}{l}\text { ZMBN } \\
91344\end{array}$ & $\begin{array}{l}\text { Morocco, } 29.0031^{\circ} \mathrm{N} \\
11.2162^{\circ} \mathrm{W}, 106 \mathrm{~m}\end{array}$ & KX874563 \\
\hline & Clade A & $\begin{array}{l}\text { two longitudinal } \\
\text { stripes }\end{array}$ & $\begin{array}{l}\text { ZMBN } \\
91718 \\
\end{array}$ & $\begin{array}{l}\text { Norway, } 61.213^{\circ} \mathrm{N} \\
1.816^{\circ} \mathrm{E}, 148 \mathrm{~m} \\
\end{array}$ & KX874572 \\
\hline & Clade A & $\begin{array}{l}\text { two longitudinal } \\
\text { stripes }\end{array}$ & $\begin{array}{l}\text { ZMBN } \\
91720 \\
\end{array}$ & $\begin{array}{l}\text { Norway, } 61.432^{\circ} \mathrm{N} \\
1.927^{\circ} \mathrm{E}, 266 \mathrm{~m} \\
\end{array}$ & KX874573 \\
\hline & Clade B & $\begin{array}{l}\text { two longitudinal } \\
\text { stripes }\end{array}$ & $\begin{array}{l}\text { ZMBN } \\
91347\end{array}$ & $\begin{array}{l}\text { Morocco, } 29.6089^{\circ} \mathrm{N} \\
10.2905^{\circ} \mathrm{W}, 102 \mathrm{~m}\end{array}$ & KX874567 \\
\hline & Clade B & $\begin{array}{l}\text { two longitudinal } \\
\text { stripes }\end{array}$ & $\begin{array}{l}\text { ZMBN } \\
111719 \\
\end{array}$ & $\begin{array}{l}\text { Morocco, } 29.6089^{\circ} \mathrm{N} \\
10.2905^{\circ} \mathrm{W}, 102 \mathrm{~m}\end{array}$ & KX874561 \\
\hline & Clade C & paired lateral dots & $\begin{array}{l}\text { ZMBN } \\
111716\end{array}$ & $\begin{array}{l}\text { Spain, Mallorca, } \\
39.72125^{\circ} \mathrm{N} \\
3.46395 \mathrm{E}^{\circ}, 10-18 \mathrm{~m}\end{array}$ & KX874569 \\
\hline & Clade C & paired lateral dots & $\begin{array}{l}\text { ZMBN } \\
111717\end{array}$ & $\begin{array}{l}\text { Spain, Mallorca, } \\
39.72125^{\circ} \mathrm{N} \\
3.46395^{\circ} \mathrm{E}, 10-18 \mathrm{~m}\end{array}$ & KX874570 \\
\hline \multirow{4}{*}{ A. brementi } & Clade D & $\begin{array}{l}\text { light-brown } \\
\text { peristomium, thin } \\
\text { transversal stripes }\end{array}$ & $\begin{array}{l}\text { ZMBN } \\
91341\end{array}$ & $\begin{array}{l}\text { Benin, } 6.0358^{\circ} \mathrm{N} \\
1.3557^{\circ} \mathrm{E}, 44 \mathrm{~m}\end{array}$ & KX874580 \\
\hline & Clade D & $\begin{array}{l}\text { light-brown } \\
\text { peristomium, thin } \\
\text { transversal stripes }\end{array}$ & $\begin{array}{l}\text { ZMBN } \\
91352\end{array}$ & $\begin{array}{l}\text { Gabon, } 2.453^{\circ} \mathrm{S} \\
9.045^{\circ} \mathrm{E}, 109 \mathrm{~m}\end{array}$ & KX874574 \\
\hline & Clade E & $\begin{array}{l}\text { dark peristomium and } \\
\text { chaetiger } 1 \text {, } \\
\text { transversal bands }\end{array}$ & $\begin{array}{l}\text { ZMBN } \\
91342\end{array}$ & $\begin{array}{l}\text { São Tomé and } \\
\text { Príncipe, } 1.6193^{\circ} \mathrm{N} \\
7.3364^{\circ} \mathrm{E}, 47 \mathrm{~m}\end{array}$ & KX874578 \\
\hline & Clade E & $\begin{array}{l}\text { dark peristomium and } \\
\text { chaetiger } 1 \text {, } \\
\text { transversal bands }\end{array}$ & $\begin{array}{l}\text { ZMBN } \\
91343\end{array}$ & $\begin{array}{l}\text { São Tomé and } \\
\text { Príncipe, } 1.6193^{\circ} \mathrm{N} \\
7.3364^{\circ} \mathrm{E}, 47 \mathrm{~m}\end{array}$ & KX874579 \\
\hline A. fauveli & Clade E & $\begin{array}{l}\text { dark peristomium and } \\
\text { chaetiger } 1 \text {, } \\
\text { transversal bands }\end{array}$ & $\begin{array}{l}\text { ZMBN } \\
91312\end{array}$ & $\begin{array}{l}\text { Cameroon, } 3.291^{\circ} \mathrm{N} \\
9.5695^{\circ} \mathrm{E}, 37 \mathrm{~m}\end{array}$ & KJ027318 \\
\hline \multirow{2}{*}{ A. brementi } & Clade F & $\begin{array}{l}2-4 \text { brown dorsal } \\
\text { spots on anterior } \\
\text { segments }\end{array}$ & $\begin{array}{l}\text { ZMBN } \\
91415\end{array}$ & $\begin{array}{l}\text { W. Sahara, } 27.0158^{\circ} \mathrm{N} \\
13.5021^{\circ} \mathrm{W}, 32 \mathrm{~m}\end{array}$ & KX874576 \\
\hline & Clade F & $\begin{array}{l}2-4 \text { brown dorsal } \\
\text { spots on anterior } \\
\text { segments }\end{array}$ & $\begin{array}{l}\text { ZMBN } \\
91414\end{array}$ & $\begin{array}{l}\text { W. Sahara, } 27.0158^{\circ} \mathrm{N} \\
13.5021^{\circ} \mathrm{W}, 32 \mathrm{~m}\end{array}$ & KX874577 \\
\hline
\end{tabular}


Table 2 (continued).

Таблица 2 (продолжение).

\begin{tabular}{|c|c|c|c|c|c|}
\hline \multirow{4}{*}{ A. brementi } & Clade F & $?$ & $\begin{array}{l}\text { ZMBN } \\
91340\end{array}$ & $\begin{array}{l}\text { Gabon, } 2.8702^{\circ} \mathrm{S} \\
9.4242^{\circ} \mathrm{E}, 105 \mathrm{~m}\end{array}$ & KX874581 \\
\hline & Clade F & $\begin{array}{l}\text { light-brown } \\
\text { peristomium, thin } \\
\text { transversal stripes }\end{array}$ & $\begin{array}{l}\text { ZMBN } \\
111724\end{array}$ & $\begin{array}{l}\text { Cape Verde, } \\
15.444^{\circ} \mathrm{N} 23.1366^{\circ} \mathrm{W}, \\
82 \mathrm{~m}\end{array}$ & KX874582 \\
\hline & Clade F & $\begin{array}{l}\text { light-brown } \\
\text { peristomium, thin } \\
\text { transversal stripes }\end{array}$ & $\begin{array}{l}\text { ZMBN } \\
111725\end{array}$ & $\begin{array}{l}\text { Nigeria, } 4.0718^{\circ} \mathrm{N} \\
6.6437^{\circ} \mathrm{E}, 40 \mathrm{~m}\end{array}$ & KX874583 \\
\hline & Clade F & $\begin{array}{l}\text { 2-4 brown dorsal } \\
\text { spots on anterior } \\
\text { segments }\end{array}$ & $\begin{array}{l}\text { ZMBN } \\
91412\end{array}$ & $\begin{array}{l}\text { Morocco, } 33.6879^{\circ} \mathrm{N} \\
7.6144^{\circ} \mathrm{W}, 55 \mathrm{~m}\end{array}$ & KX874575 \\
\hline Aponuphis sp. & Clade F & $?$ & $\begin{array}{l}\text { USNM } \\
1207008\end{array}$ & $\begin{array}{l}\text { Banyuls, France, } \\
42.4892^{\circ} \mathrm{N} 3.1873^{\circ} \mathrm{E}, \\
70 \mathrm{~m}\end{array}$ & KJ027319ª \\
\hline \multirow{5}{*}{ A. ornata } & Clade I & "horse-shoe" pattern & $\begin{array}{l}\text { ZMBN } \\
111727 \\
\end{array}$ & $\begin{array}{l}\text { Morocco, } 32.4725^{\circ} \mathrm{N} \\
9.2744^{\circ} \mathrm{W}, 40 \mathrm{~m}\end{array}$ & KX874586 \\
\hline & Clade I & "horse-shoe" pattern & $\begin{array}{l}\text { ZMBN } \\
111728 \\
\end{array}$ & $\begin{array}{l}\text { Morocco, } 33.6879^{\circ} \mathrm{N} \\
7.6144^{\circ} \mathrm{W}, 55 \mathrm{~m}\end{array}$ & KX874585 \\
\hline & Clade I & "horse-shoe" pattern & $\begin{array}{l}\text { ZMBN } \\
91354\end{array}$ & $\begin{array}{l}\text { Morocco, } 32.4725^{\circ} \mathrm{N} \\
9.2744^{\circ} \mathrm{W}, 40 \mathrm{~m}\end{array}$ & KX874587 \\
\hline & Clade I & "horse-shoe" pattern & $\begin{array}{l}\text { ZMBN } \\
91357\end{array}$ & $\begin{array}{l}\text { Morocco, } 33.6879^{\circ} \mathrm{N} \\
7.6144^{\circ} \mathrm{W}, 55 \mathrm{~m}\end{array}$ & KX874588 \\
\hline & Clade I & "horse-shoe" pattern & $\begin{array}{l}\text { ZMBN } \\
91355\end{array}$ & $\begin{array}{l}\text { Morocco, } 32.4725^{\circ} \mathrm{N} \\
9.2744^{\circ} \mathrm{W}, 40 \mathrm{~m}\end{array}$ & KX874589 \\
\hline Aponuphis sp. & Clade G & $\begin{array}{l}\text { colorless } \\
\text { peristomium, thin } \\
\text { transversal stripes }\end{array}$ & $\begin{array}{l}\text { ZMBN } \\
111729\end{array}$ & $\begin{array}{l}\text { Senegal, } 14.4596^{\circ} \mathrm{N} \\
17.6104^{\circ} \mathrm{W}, 498 \mathrm{~m}\end{array}$ & KX874590 \\
\hline Aponuphis sp. & Clade G & $\begin{array}{l}\text { colorless } \\
\text { peristomium, thin } \\
\text { transversal stripes }\end{array}$ & $\begin{array}{l}\text { ZMBN } \\
111730\end{array}$ & $\begin{array}{l}\text { Mauritania, } \\
17.3388^{\circ} \mathrm{N} \\
16.7587^{\circ} \mathrm{W}, 518 \mathrm{~m}\end{array}$ & KX874591 \\
\hline A. bilineata & Clade H & $?$ & & Qawra, Malta & AY838824 ${ }^{\mathrm{b}}$ \\
\hline \multirow{2}{*}{$\begin{array}{l}\text { Onuphis } \\
\text { elegans } \\
\text { (Johnson, } \\
1901 \text { ) }\end{array}$} & & & & not reported & AY838839 ${ }^{b}$ \\
\hline & & & $\begin{array}{l}\text { USNM } \\
1121747 \\
\end{array}$ & Washington, USA & GQ478128 \\
\hline $\begin{array}{l}\text { Onuphis } \\
\text { iridescens } \\
\text { (Johnson, } \\
1901 \text { ) } \\
\end{array}$ & & & & Bamfield, Canada & HM746715 d \\
\hline $\begin{array}{l}\text { O. cf. } \\
\text { iridescens }\end{array}$ & & & $\begin{array}{l}\text { USNM } \\
1121744 \\
\end{array}$ & California, USA & GQ478127 \\
\hline \multirow{2}{*}{$\begin{array}{l}\text { Onuphis } \\
\text { opalina } \\
\text { (Verrill, 1873) }\end{array}$} & & & $\begin{array}{l}\text { USNM } \\
1207006\end{array}$ & Massachusetts, USA & KJ027343 ${ }^{\mathrm{a}}$ \\
\hline & & & $\begin{array}{l}\text { ZMBN } \\
91332\end{array}$ & $\begin{array}{l}\text { Newfoundland Great } \\
\text { Bank, Canada }\end{array}$ & KJ027344 \\
\hline $\begin{array}{l}\text { Onuphis } \\
\text { shirikishinaen } \\
\text { sis (Imajima, } \\
1960 \text { ) }\end{array}$ & & & $\begin{array}{l}\text { ZMBN } \\
91333\end{array}$ & $\begin{array}{l}\text { Primorsky Krai, } \\
\text { Russia }\end{array}$ & $\mathrm{KJ} 027345^{\mathrm{a}}$ \\
\hline
\end{tabular}


Table 2 (continued). Таблица 2 (продолжение).

\begin{tabular}{|c|c|c|c|c|c|}
\hline Species & $\begin{array}{l}\text { Clade } \\
\text { code }\end{array}$ & Color pattern & $\begin{array}{l}\text { Catalo- } \\
\text { gue } \\
\text { number }\end{array}$ & Country & $\begin{array}{l}\text { GenBank } \\
\text { Accession } \\
\text { Number }\end{array}$ \\
\hline $\begin{array}{l}\text { Hyalinoecia } \\
\text { tubicola (O.F. } \\
\text { Müller, 1776) }\end{array}$ & & & $\begin{array}{l}\text { ZMBN } \\
91320\end{array}$ & Bergen, Norway & KJ027333 ${ }^{\mathrm{a}}$ \\
\hline $\begin{array}{l}\text { Nothria } \\
\text { conchylega } \\
\text { (Sars, 1835) }\end{array}$ & & & $\begin{array}{l}\text { ZMBN } \\
91331\end{array}$ & $\begin{array}{l}\text { Kuril Islands, Sea of } \\
\text { Okhotsk, Russia, } \\
46.9712^{\circ} \mathrm{N} \\
152.2017^{\circ} \mathrm{E}, 245 \mathrm{~m}\end{array}$ & KJ027342 ${ }^{\mathrm{a}}$ \\
\hline
\end{tabular}

a - sequences from Budaeva et al. (2016), b — sequences from Struck et al. (2006), c — sequences from Zanol et al. (2010), d - sequences from Paul et al. (2010).

a - последовательности из Budaeva et al. (2016), b - последовательности из Struck et al. (2006), с последовательности из Zanol et al. (2010), d — последовательности из Paul et al. (2010).

tion of the species tree based on p-distance. Bootstrap was performed in 100,000 iterations to provide the node support. Automatic Barcode Gap Discovery (ABGD) (Puillandre et al., 2012) based on pairwise differences available at http://www.abi.snv.jussieu.fr/public/abgd/ was used to define species boundaries.

\section{Molecular analysis}

The dataset had 397 aligned positions with 129 parsimony informative positions and 161 variable sites. Aponuphis appeared monophyletic with 100 bootstrap support. Onuphis appeared monophyletic and sister to Aponuphis with high bootstrap support (BS 96).

The ABGD analysis of the $16 \mathrm{~S}$ rDNA dataset recovered nine potential species of Aponuphis (Fig. 3A-I). We were not able to find morphological differences between the clades identified as $A$. bilineata and $A$. brementi and therefore treat them as species complexes which require further investigation and formal description of potentially new species. Pairwise genetic distances between the putative species are shown in Table 3.

The Aponuphis bilineata species complex formed a monophyletic clade with 100 bootstrap support. This clade was subdivided into three subclades (Fig. 3A-C) with 3.9-5.4\% genetic distances between them. Specimens with the typical two longitudinal stripes along the body were separated into two clades: clade A (BS 100) found in the North Sea and in the northwestern African waters and clade B (BS 100) reported from Morocco. Two specimens from Mediterranean (Spain) with previously unknown color pattern of paired lateral dots formed clade C (BS 100).

The Aponuphis brementi species complex (BS 96) also consisted of three monophyletic subclades (Fig. 3D-F) with 5.2-9.3\% genetic distances between them. Clade D (BS 100) comprised two specimens from Gabon and Benin with indistinct coloration of slightly brownish peristomium and thin transversal stripes on the anterior body segments. Clade E (BS 100) combined specimens from São Tomé and Príncipe and A. fauveli previously reported from Cameroon by Budaeva et al. (2016). All specimens had a distinct color pattern of a darkly pigmented peristomium and chaetiger 1 with subsequent brownish dorsal stripes located at the segment borders. Clade F (BS 99) was of wide distribution from the French coast to Gabon and combined specimens with two color morphs: previously described very distinct color pattern of paired dorsal dark brown spots and the pattern similar to the specimens from the clade $\mathrm{D}$ with indistinct dorsal transversal bands.

Clade G (BS 100) comprised two specimens from the deep (about $500 \mathrm{~m}$ ) localities off Mauritania and Senegal. The specimens shared the presence of branchiae starting from chaetiger 5 


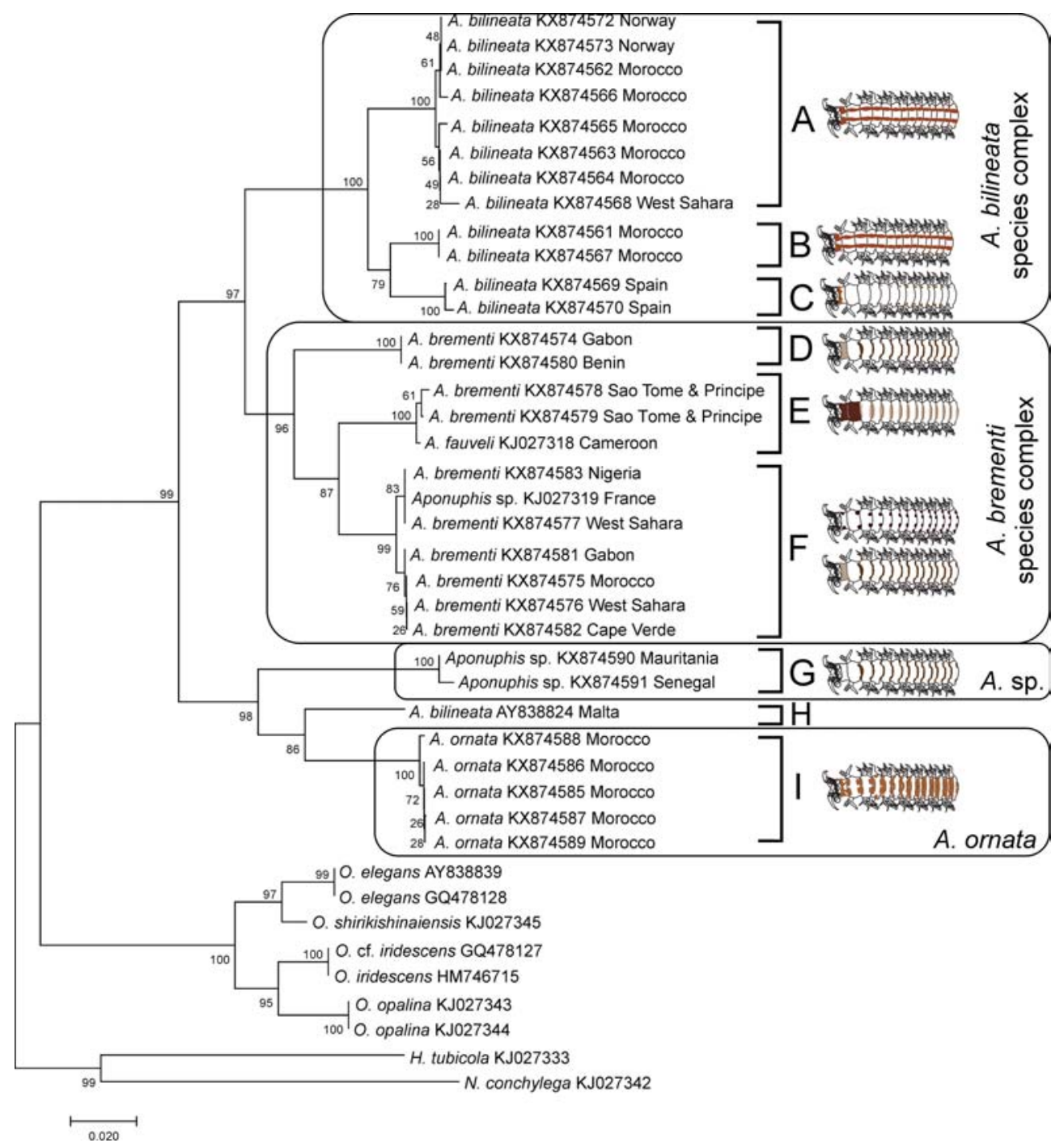

Fig. 3. Phylogenetic tree resulting from the Neighbor Joining analysis of 16S rDNA sequences of Aponuphis species. Numbers on nodes indicate bootstrap support. Capital letters correspond with the clades discussed in the text.

Рис. 3. Филогенетическое дерево, построенное методом ближайшего соседа на основе последовательностей гена $16 \mathrm{~S}$ рДНК для видов Aponuphis. Значения в узлах дерева отображают поддержку бутстреп. Заглавные буквы соответствуют кладам, обсуждаемым в тексте.

and possibly represent a new species. The color pattern of the two studied specimens was indistinct with the peristomium lacking pigmentation and transversal stripes present on anterior chaetigers. Clade $\mathrm{H}$ was represented by a single specimen reported from Malta by Struck et al.
(2006) under the name $A$. bilineata. The color pattern of this specimen is unknown, and its taxonomic position is unresolved. Clade I (BS 100) combined all specimens from Morocco with typical "horse-shoe" color pattern on anterior segments identified as Aponuphis ornata. 
Table 3. Estimates of evolutionary divergence over 16S rDNA sequence pairs between the Aponuphis clades revealed in the analysis. Clade codes correspond with those on Fig. 3.

Таблица 3. Оценка эволюционных дистанций между последовательностями гена 16S рДНК у видов Aponuphis. Обозначения клад соответствуют таковым на рис. 3.

\begin{tabular}{|l|c|c|c|c|c|c|c|c|c|}
\hline & \multicolumn{3}{|c|}{$\begin{array}{c}\text { A. bilineata species } \\
\text { complex }\end{array}$} & \multicolumn{3}{c|}{$\begin{array}{c}\text { A. brementi species } \\
\text { complex }\end{array}$} & $\begin{array}{c}\text { Aponu- } \\
\text { phis sp. }\end{array}$ & $\begin{array}{c}\text { A. bilineata } \\
\text { (Struck et } \\
\text { al., 2006) }\end{array}$ & $\begin{array}{c}\text { A. or- } \\
\text { nata }\end{array}$ \\
\hline $\begin{array}{l}\text { Clade } \\
\text { code }\end{array}$ & $\mathrm{A}$ & $\mathrm{B}$ & $\mathrm{C}$ & $\mathrm{D}$ & $\mathrm{E}$ & $\mathrm{F}$ & $\mathrm{G}$ & $\mathrm{H}$ & $\mathrm{I}$ \\
\hline $\mathrm{A}$ & & & & & & & & & \\
\hline $\mathrm{B}$ & $4.9 \%$ & & & & & & & & \\
\hline $\mathrm{C}$ & $5.4 \%$ & $3.9 \%$ & & & & & & & \\
\hline $\mathrm{D}$ & $11.7 \%$ & $11.8 \%$ & $12.3 \%$ & & & & & & \\
\hline $\mathrm{E}$ & $12.3 \%$ & $13.0 \%$ & $11.0 \%$ & $9.3 \%$ & & & & & \\
\hline $\mathrm{F}$ & $12.0 \%$ & $12.1 \%$ & $11.0 \%$ & $6.3 \%$ & $5.2 \%$ & & & & \\
\hline $\mathrm{G}$ & $16.7 \%$ & $17.7 \%$ & $16.9 \%$ & $15.2 \%$ & $15.8 \%$ & $15.9 \%$ & & & \\
\hline $\mathrm{H}$ & $15.7 \%$ & $16.5 \%$ & $16.9 \%$ & $14.0 \%$ & $17.4 \%$ & $15.0 \%$ & $11.2 \%$ & & \\
\hline $\mathrm{I}$ & $15.7 \%$ & $16.4 \%$ & $16.9 \%$ & $15.3 \%$ & $17.4 \%$ & $17.8 \%$ & $10.6 \%$ & $7.5 \%$ & \\
\hline
\end{tabular}

\section{Taxonomic account}

\author{
Aponuphis bilineata (Baird, 1870) \\ species complex \\ Figs. 1, 2, 4, 5.
}

Hyalinoecia bilineata Baird, 1870: 358-359; Rioja, 1918: 44; Fauvel, 1936: 51; Bellan, 1960: 18; Intes, Le Loeuff, 1975: 309.

Hyalinoecia rubra Langerhans, 1880: 292.

Aponuphis bilineata. - Kucheruk, 1978: 91; Aguirrezabalaga et al., 2002: 27; Arias, Paxton, 2015: 358-360.

MATERIAL EXAMINED:

Western Africa, RV Fridtjof Nansen:ZMBN 91344, Morocco, St. GR37 (1 DNA voucher); ZMBN 91345, Morocco, St. GR37 (1 DNA voucher); ZMBN 91346, Morocco, St. GR40 (1 DNA voucher); ZMBN 91348, Morocco, St. GR49 (1 DNA voucher); ZMBN 111713, West Sahara, St. GR28 (1 DNA voucher); ZMBN 111714, Morocco, St. GR37 (1 DNA voucher); ZMBN 111719, Morocco, St. GR40 (1 DNA voucher); ZMBN 91413, Morocco, St. GR37 (1 DNA voucher); ZMBN 91348, Morocco, St. GR-49 (1); ZMBN 91344, West Sahara, St. GR28 (8); ZMBN 91347, Morocco, St. GR40 (6); ZMBN 91341, Morocco, St. SL38 (5, 1 on SEM stub); ZMBN 91342, Guinea, St. 7GU-3C (1); ZMBN 91415, Morocco, St. GR37 (1 on SEM stub); ZMBN 91340, São Tomé and Príncipe, St. E5-7-5B (10).

Mediterranean: ZMBN 111716, Spain, off Mallorca, $39.72125^{\circ} \mathrm{N} 3.46395 \mathrm{E}^{\circ}$, 10-18 m (1 DNA voucher); ZMBN 111717, Spain, off Mallorca, $39.72125^{\circ} \mathrm{N} 3.46395 \mathrm{E}^{\circ}, 10-18 \mathrm{~m}$ (1 DNA voucher).

North Sea: ZMBN 91718, Norway, St. SFB$11 \_11,61.213^{\circ} \mathrm{N} 1.816^{\circ} \mathrm{E}, 148 \mathrm{~m}$ (1 DNA voucher); ZMBN 91720, Norway, St. SFNE$01 \_11,61.432^{\circ} \mathrm{N} 1.927^{\circ} \mathrm{E}, 266 \mathrm{~m}$ (1 DNA voucher).

TYPE LOCALITY: off Cornwall, Great Britain, $73 \mathrm{~m}$.

REMARKS: Antennae reach chaetiger 1015 (Fig. 4A). First 6-7 chaetigers with tridentate falcigers (Fig. 4E, F), bidentate falcigers were reported in previous descriptions (Arias, Paxton, 2015) but were absent in the studied material. Subulate ventral cirri present on the first five chaetigers (Fig. 4B, C). Branchiae simple strap-like, starting from chaetiger 5 . Subacicular hooks from chaetiger 10 (Fig. 4D). Three clades are recovered within $A$. bilineata (Fig. $3 \mathrm{~A}-\mathrm{C}$ ). Two clades (A and C) have the typical color pattern of two large spots on the peristomium continuing into two longitudinal orange stripes on the dorsal side. Additional lateral 

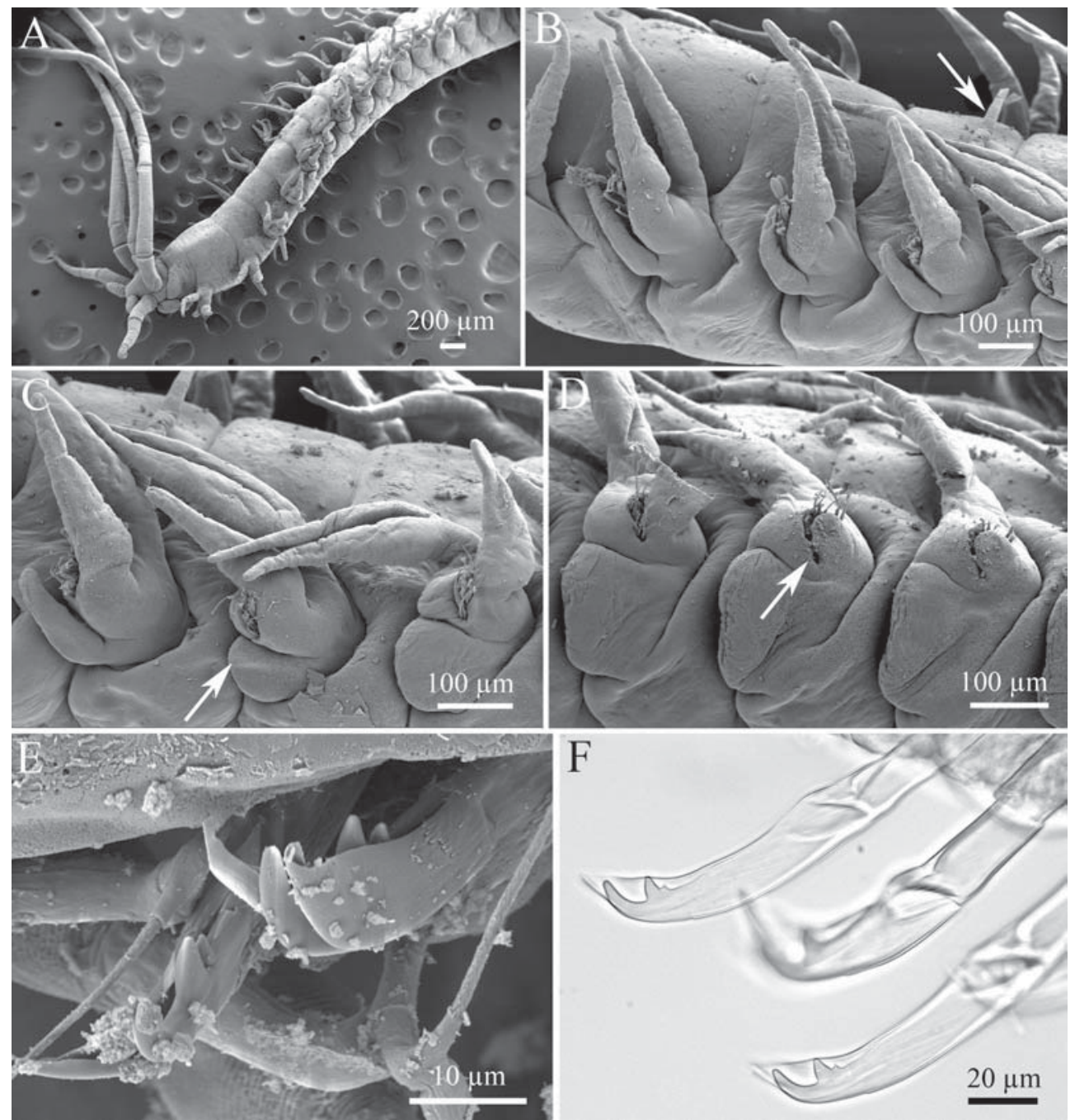

Fig. 4. Morphology of Aponuphis bilineata. A - anterior part of the body, lateral view; B - parapodia of chaetigers 3-5, arrow indicates the first branchia on parapodium $5 ; \mathrm{C}$ - parapodia of chaetigers $5-7$, arrow indicates ventral glandular pad on parapodium 6; D - parapodia of chaetigers 9-11, arrow indicates subacicular hooks on parapodium 10; E, F - pseudocompound falcigers from anterior parapodia. A-E scanning electron micrographs; F - light micrograph.

Рис. 4. Морфологические признаки Aponuphis bilineata. А - передний отдел тела, вид сбоку; В параподии 3-5-го сегментов, стрелка указывает на первую жабру на 5-м сегменте; C - параподии 57-го сегментов, стрелка указывает на вентральную железистую подушечку на 6-м сегменте; D параподии 9-11-го сегментов, стрелка указывает на субацикулярные крючья на 10-м сегменте; E, F псевдосочленные крючковидные щетинки на передних параподиях. А-Е — сканирующие электронные микрофотографии; F - световая микрофотография.

pigmented spots are visible on each segment at the bases of the parapodia (Figs 1A, 2A). This pattern was named by Arias \& Paxton (2015) as morph (1). Morph (2) was described as "peri- stomium and first 3-4 chaetigers with two large brownish spots almost filling dorsal surface of segment, sometimes coalescing medially; from chaetiger 4-5 to median region two longitudinal 


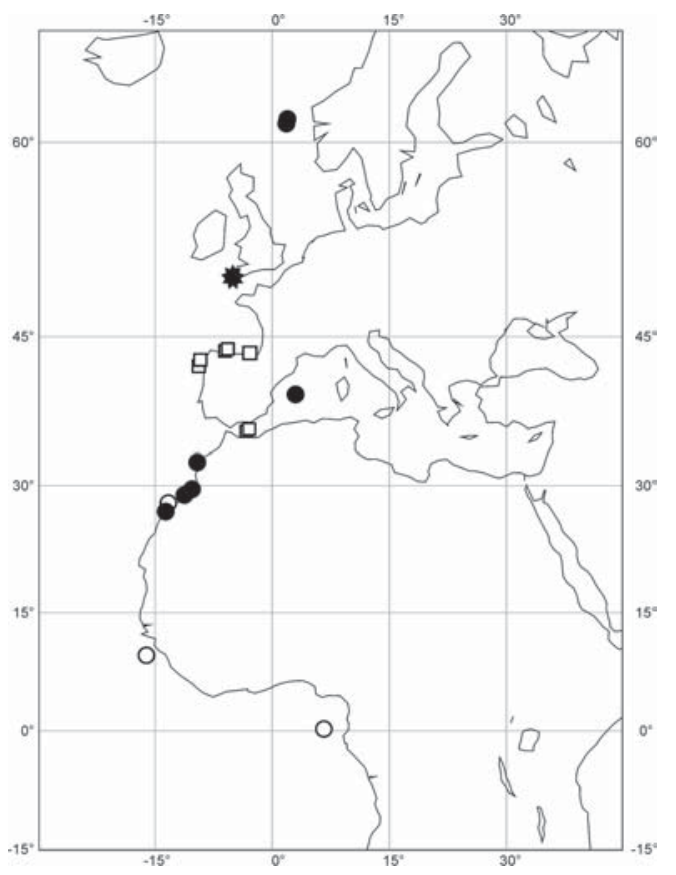

Fig. 5. Distribution of Aponuphis bilineata. Black star indicates the type locality; black circles indicate localities from which genetic data were available; white circles indicate localities without genetic data; white squares indicate data from literature (Arias, Paxton, 2015).

Рис. 5. Распространение Aponuphis bilineata. Черной звездой отмечено типовое местонахождение; черными кругами отмечены станции, для которых получены молекулярно-генетические данные; белыми кругами отмечены станции, для которых молекулярно-генетических данных нет; белыми квадратами отмечены данные из литературы (Arias, Paxton, 2015).

dorsal pigmented stripes discoursing laterally close to parapodia" (Arias, Paxton, 2015). This morph was not present in the studied material. Clade C comprised specimens collected off Mallorca, Spain with slightly pigmented peristomium and a pair of lateral pigmented dots on each segment (Figs 1B, 2B) representing the third previously unknown color morph in this species complex.

DISTRIBUTION: East Atlantic, North Sea, Mediterranean, in western Africa from Morocco to São Tomé and Príncipe. Clade A - North Sea, off Morocco and Western Sahara, 101-266 m; clade B - off Morocco, $102 \mathrm{~m}$; clade C off Mallorca, Spain, 10-18 m (Fig. 5).

\section{Aponuphis brementi (Fauvel, 1916) species complex}

Figs. 1, 2, 6, 7.

Hyalinoecia brementi Fauvel, 1916: 5, Figs. 2-3. Aponuphis brementi. - Paxton, 1986: 54; Arias, Paxton, 2015: 360-361, Fig. 7C.

Hyalinoecia fauveli Rioja, 1918: 45; Fauvel, 1923: 424, Fig. 167a-h; 1936: 52; Bellan, 1960: 18; Intes, Le Loeuff, 1975: 309; Amoureux, 1977: 55; Kirkegaard, 1988: 33.

Hyalinoecia fauveli africana Rullier, 1965: 37; Kirkegaard, 1988: 33.

Aponuphis fauveli. — Paxton, 1986: 54; Aguirrezabalaga et al., 2002: 27.

MATERIAL EXAMINED: RV Fridtjof Nansen: ZMBN 91340, Gabon, St. 5G-12 (1 DNA voucher on SEM stub); ZMBN 91341, Benin, St. 7BN-1E (1 DNA voucher); ZMBN 91342, São Tomé and Príncipe, St. 7SP-03 (1 DNA voucher); ZMBN 91343, São Tomé and Príncipe, St. 7SP03 (1 DNA voucher); ZMBN 91352, Gabon, St. 5G-10 (1 DNA voucher on SEM stub); ZMBN 91412, Morocco, St. GR56 (1 DNA voucher on SEM stub); ZMBN 91414, Western Sahara, St. GR27 (1 DNA voucher); ZMBN 91415, Western Sahara, St. GR27 (1 DNA voucher); ZMBN 111724, Cape Verde, St. SL02 (1 DNA voucher); ZMBN 111725, Nigeria, St. 6N-15 (1 DNA voucher); ZMBN 91312, Cameroon, St. 5C-11 (1); ZMBN 91349, São Tomé and Príncipe, St. 5SP-03 (1); ZMBN 111731, Angola, St. 7AN-01 (8, 2 on SEM stub); ZMBN 111732, Angola, St. 7AN-02 (1); ZMBN 116036, Angola, St. 7AN-04(6);ZMBN 116037, Cape Verde, St. SL02 (1); ZMBN 116039, Ghana, St. 7GH-1E(1);ZMBN 116040 , Ghana, St. 7GH-04 (2); ZMBN 116041, Ghana, St. 7GH-7D (1); ZMBN 116043, Morocco, St. GR56 (2); ZMBN 116044, Nigeria, St. 5N-17 (1); ZMBN 116045, Nigeria, St. 6N-15 (2); ZMBN 116046, Nigeria, St. 6N-23 (1).

TYPE LOCALITY: Monaco, Mediterranean.

REMARKS: Antennae reach chaetiger 1520 (Fig. 6A). First six chaetigers with tridentate pseudocompound falcigers (Fig. 6D). Bidentate falcigers reported by Arias and Paxton 

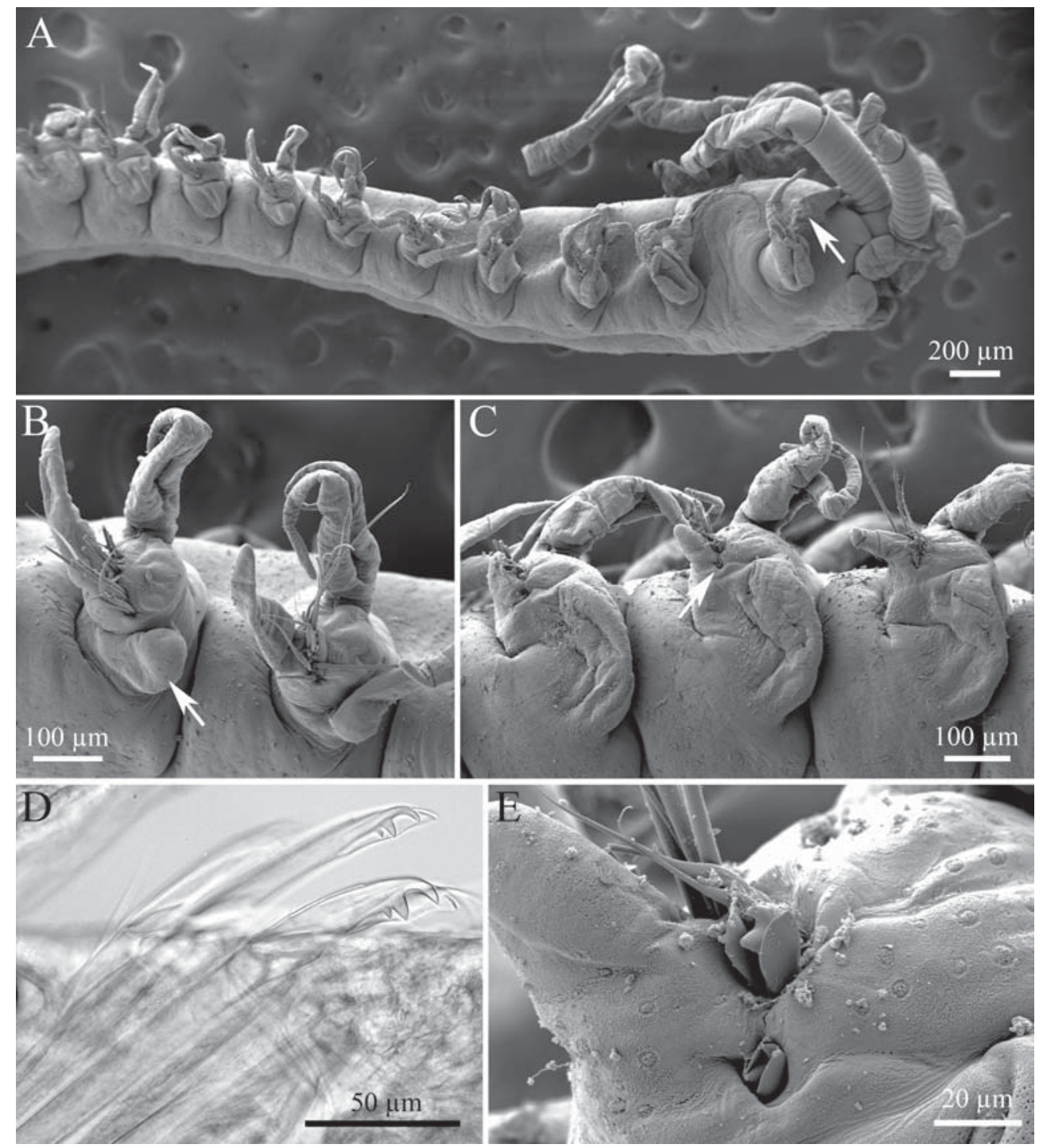

Fig. 6. Morphology of Aponuphis brementi. A - anterior part of the body, lateral view, arrow indicates the first branchia on chaetiger 1; B - parapodia of chaetigers 7-6, arrow indicates ventral glandular pad on parapodium 7; $\mathrm{C}$ - parapodia of chaetigers $12-14$, arrow indicates subacicular hooks on parapodium 13; D - tridentate pseudocompound falcigers; E - subacicular hooks. A-C, E - scanning electron micrographs; D - light micrograph.

Рис. 6. Морфологические признаки Aponuphis brementi. А — передний отдел тела, вид сбоку, стрелка указывает на первую жабру на 1-м сегменте; В - параподии 6-7-го сегментов, стрелка указывает на вентральную железистую подушечку на 7-м сегменте; С — параподии 12-14-го сегментов, стрелка указывает на субацикулярные крючья на 13-м сегменте; Е - трехзубые псевдосочлененные щетинки; Е - субацикулярные крючья. А-C, E - сканирующие электронные микрофотографии, D световая микрофотография.

(2015) were not observed. Subulate ventral cirri present on anterior six chaetigers (Fig. 6B). Branchiae starting from chaetiger 1-2. One small specimen (width $0.8 \mathrm{~mm}$ ) had branchiae from chaetiger 4. Later appearance of branchiae was reported in juveniles of $A$. ornata and $A$. bre- 


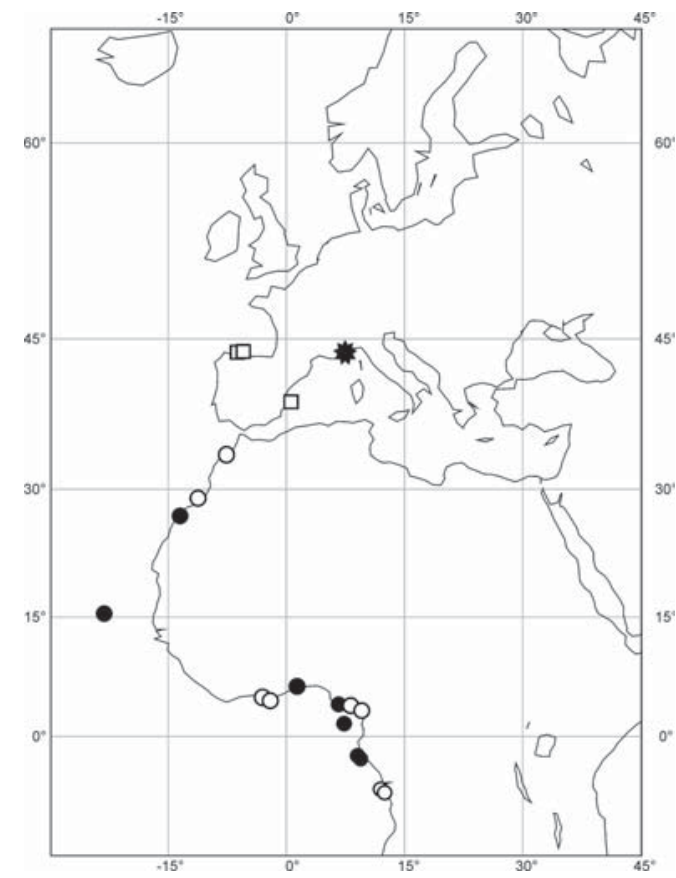

Fig. 7. Distribution of Aponuphis brementi. Black star indicates the type locality; black circles indicate localities from which genetic data were available; white circles indicate localities without genetic data; white squares indicate data from literature (Arias, Paxton, 2015).

Рис. 7. Распространение Aponuphis brementi. Черной звездой отмечено типовое местонахождение; черными кругами отмечены станции, для которых получены молекулярно-генетические данные; белыми кругами отмечены станции, для которых молекулярно-генетических данных нет; белыми квадратами отмечены данные из литературы (Arias, Paxton, 2015).

menti by Arias \& Paxton (2015). Subacicular hooks from chaetiger 12-13 (Fig. 6C, E). Three color morphs were found in A. brementi. Seven specimens from Morocco (GR27, GR37, GR56) had the typical pattern with two large dorsolateral dark brown spots on the peristomium and all subsequent chaetigers (Figs 1D, 2D). In specimens from Ghana (7GH-1E), Cameroon (5C-11), São Tomé and Príncipe (7SP-03) and Angola (7AN-01, 7AN-04), the peristomium and the first chaetiger were completely dark in color with subsequent chaetigers bearing thin transversal bands (Figs 1E, 2E). A similar color morph has been reported by Kirkegaard (1988) for Hyalinoecia fauveli africana, a subspecies subsequently synonymized with $A$. brementi by Arias \& Paxton (2015). Seventeen specimens from Cape Verde (SL02), Ghana (7GH-7D), Benin $(7 \mathrm{BN}-1 \mathrm{E})$, Nigeria $(6 \mathrm{~N}-15,5 \mathrm{~N}-17,6 \mathrm{~N}-$ 23), Gabon (5G-12) and Angola (7AN-2, 7AN$04)$ were with slightly pigmented peristomium and thin dark transversal stripes on anterior segments (Figs 1F, 2F). Clade E comprised specimens with a dark peristomium and first segment (Fig. 3E). Clade F combined specimens with two color morphs: the typical morph with dorsal brown spots and the morph with thin transversal stripes (Fig. 3F). The latter morph was also found in clade D (Fig. 3D).

DISTRIBUTION: Clade D-offBenin and Gabon, 44-109 m; clade E - offCameroon and São Tomé and Príncipe, 37-47 m; clade F widely distributed in Eastern Atlantic from France to Gabon, depth range in studied material 32-156 m (Fig. 7).

\section{Aponuphis ornata (Fauvel, 1928)}

Figs. 1, 2, 8, 9.

Hyalinoecia bilineata ornata Fauvel, 1928:12; 1936 :

52, Fig. 3.

Aponuphis ornata. - Paxton, 1986: 54; Arias, Paxton, 2015: 361-363, Figs 7D-E, 8, 9.

MATERIAL EXAMINED: RV Fridtjof Nansen: ZMBN 91354, Morocco, St. GR50 (1 DNA voucher); ZMBN 91355, Morocco, St. GR50 (1 DNA voucher); ZMBN 91357, Morocco, St. GR56 (1 DNA voucher); ZMBN 111727, Morocco, St. GR50 (1 DNA voucher, on SEM stub); ZMBN 111728, Morocco, St. GR56 (1 DNA voucher, on SEM stub); ZMBN 91353, Morocco, St. GR50 (1); ZMBN 91356, Morocco, St. GR56 (1).

TYPE LOCALITY: off Morocco, northwestern Africa.

REMARKS: Antennae reaching chaetigers 10-15 (Fig. 8A). First 5-6 pairs of parapodia with bi- and tridentate pseudocompound falcigers (Fig. 8D, E). First five chaetigers with subulate ventral cirri (Fig. 8B). Branchiae from chaetiger 4-5, simple, strap-like. Subacicular 

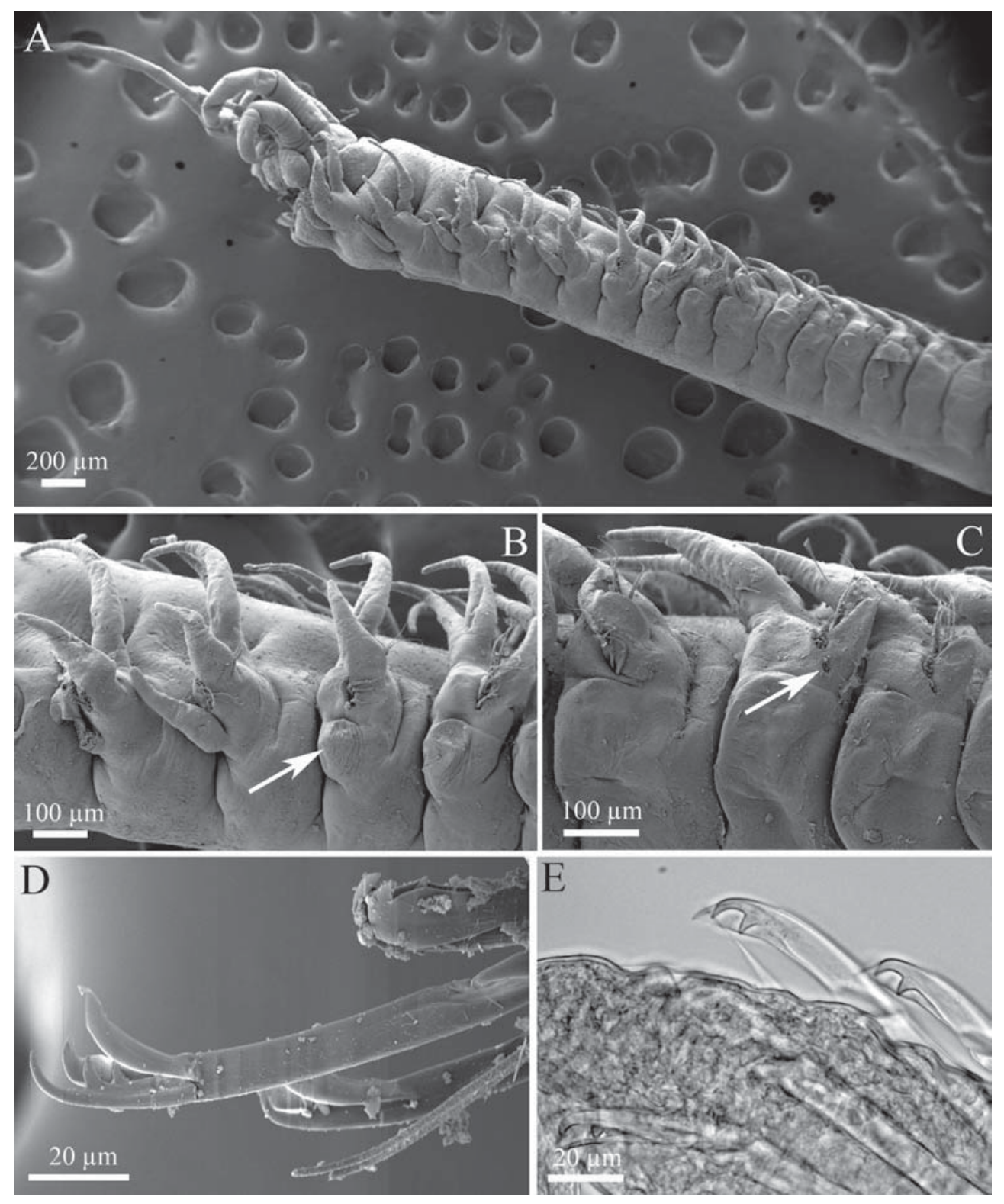

Fig. 8. Morphology of Aponuphis ornata. A - anterior part of the body, lateral view; B - parapodia of chaetigers 3-6, arrow indicates ventral glandular pad on parapodium 6; $\mathrm{C}-$ parapodia of chaetigers 9-11, arrow indicates subacicular hooks on parapodium 10; D - tridentate pseudocompound falciger; $\mathrm{E}-$ bidentate pseudocompound falcigers. A-D - scanning electron micrographs; E - light micrograph.

Рис. 8. Морфологические признаки Aponuphis ornata. А - передний отдел тела, вид сбоку; В параподии 3-6-го сегментов, стрелка указывает на вентральную железистую подушечку на 6-м сегменте; C - параподии 9-11-го сегментов, стрелка указывает на субацикулярные крючья на 10-м сегменте; D - трехзубая псевдосочлененная крючковидная щетинка; $\mathrm{G}$ - двузубые псевдосочлененные крючковидные щетинки. A-D — сканирующие электронные микрофотографии; Е - световая микрофотография. 


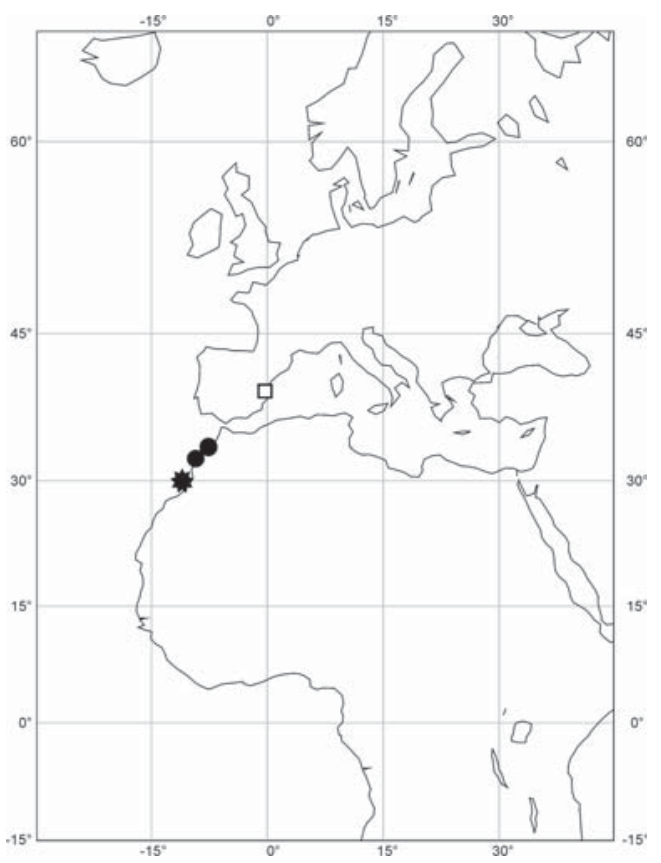

Fig. 9. Distribution of Aponuphis ornata. Black star indicates the type locality; black circles indicate localities from which genetic data were available; white square indicates data from literature (Arias, Paxton, 2015).

Рис. 9. Распространение Aponuphis ornata. Черной звездой отмечено типовое местонахождение; черными кругами отмечены станции, для которых получены молекулярно-генетические данные; белым квадратом отмечены данные из литературы (Arias, Paxton, 2015).

hooks from chaetiger 10 (Fig. 8C). All studied specimens were collected close to the type locality and had the typical color pattern. Peristomium with two large dorsal spots fusing medially; anterior chaetigers with "horse-shoe" pattern. Each "horse-shoe" spot is formed by pigmentation on adjacent chaetigers: two lateral square spots at the posterior margin of an anterior chaetiger and a transversal band on the anterior margin of a posterior chaetiger. Posterior chaetigers with wide pigmented transversal bands (Figs 1C, 2C).

DISTRIBUTION: East Atlantic, off Morocco, Bay of Biscay and Atlantic Iberia, Western and Central Mediterranean Sea (Arias, Pax- ton, 2015). Depth range in studied material 40$55 \mathrm{~m}$ (Fig. 9).

\section{Aponuphis sp.}

Figs. 10, 11.

MATERIAL EXAMINED: RV Fridtjof Nansen: ZMBN 111729, Senegal, St. GR08 (1 DNA voucher on SEM stub); ZMBN 111730 , Mauritania, St. GR11 (1 DNA voucher).

DESCRIPTION: Two incomplete studied specimens 1.0 and $0.8 \mathrm{~mm}$ wide consisting of 37 and 44 chaetigers respectively. Prostomium rounded with ovoid frontal lips. Antennae relatively short, reaching chaetiger 7-10 (Fig. 10A). Palps reaching chaetiger $8-10$. Ceratophores of lateral antennae with seven rings. First six pairs of parapodia modified, directed laterally. Branchiae simple, strap-like from chaetiger 5 (Fig. 10B). Exclusively tridentate pseudocompound falcigers with short pointed hoods present on first four pairs of parapodia (Fig. 10C). Fourth pair of parapodia with only one falciger. Pectinate chaetae with 9-11 distal denticles, from chaetiger 10. Subacicular hooks from chaetiger 10. Color pattern of dorsal transversal thin stripes on anterior chaetigers.

DISTRIBUTION: Northeastern African waters from Mauritania to Senegal. Depth range 498-518 m (Fig. 11).

\section{Discussion}

The polychaete fauna of western African waters, including the onuphid fauna, is largely understudied. Many of the African onuphids have been described in the early XX century (Augener, 1918; Fauvel, 1928). The names of species described from European waters were traditionally used in identification of the local African fauna. Application of scanning electron microscopy and molecular tools most probably should lead to the discovery of a high diversity of annelids in western African waters. One example of such hidden diversity has been uncovered in the recent study of another onuphid genus, Diopatra, revealing at least six new species in 

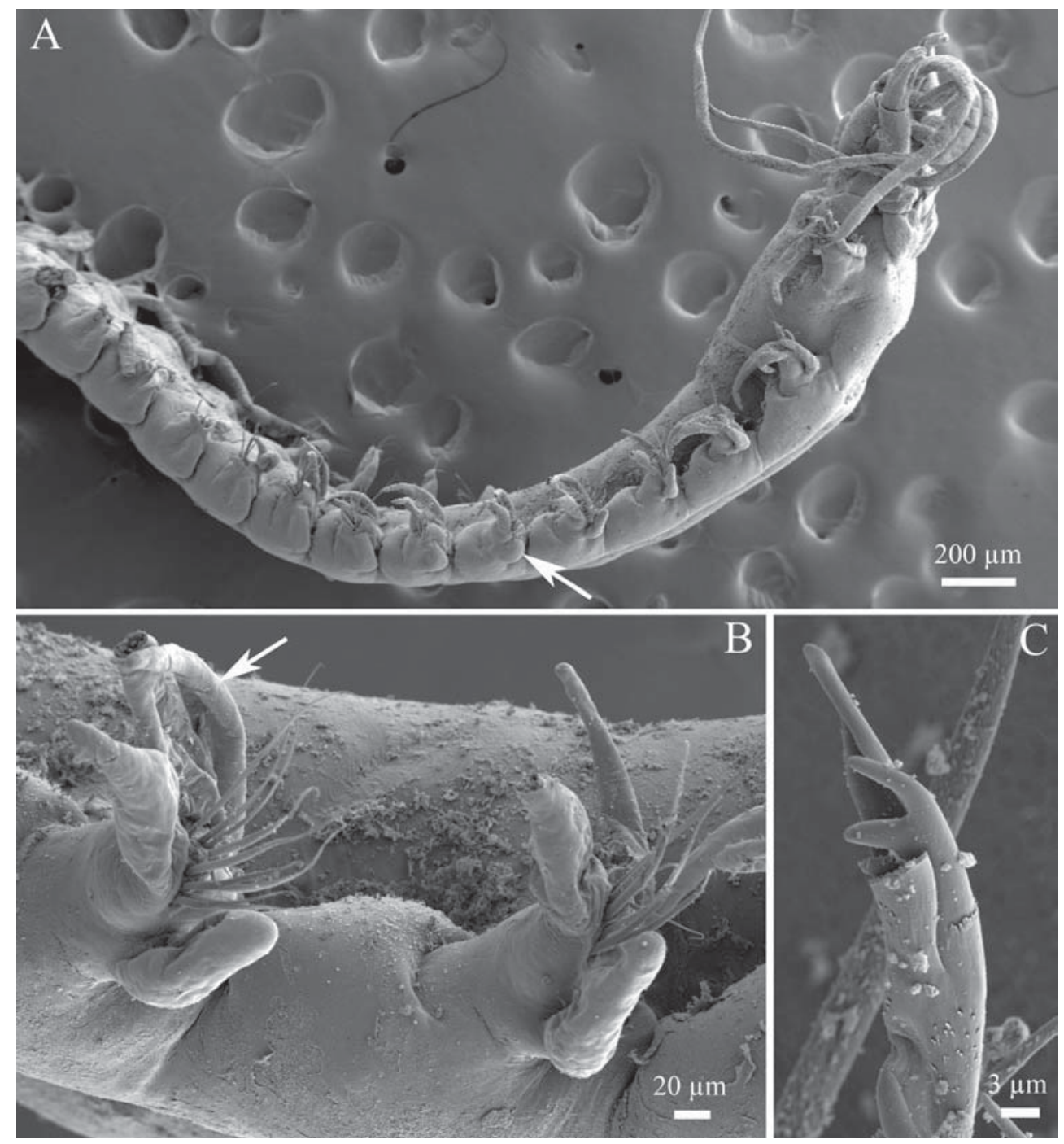

Fig. 10. Morphology of Aponuphis sp. - anterior part of the body, lateral view, arrow indicates ventral glandular pad on chaetiger 6 ; B - parapodia of chaetigers $4-5$, arrow indicates the first branchia on parapodium 5; $\mathrm{C}$ - tridentate pseudocompound falciger. A-C - scanning electron micrographs.

Рис. 10. Морфологические признаки Aponuphis sp. А - передний отдел тела, вид сбоку, стрелка указывает на вентральную железистую подушечку на 6-м сегменте; В - параподии 4-5-го сегментов, стрелка указывает на первую жабру на 5 -м сегменте; $\mathrm{C}$ - трехзубая псевдосочлененная крючковидная щетинка. A-C - сканирующие электронные микрофотографии.

western Africa based on morphological and molecular data (Hektoen, Budaeva, 2016).

Aponuphis has a relatively simple external morphology with slightly modified anterior parapodia, only four types of chaetae, and simple branchiae. All diagnostic characters are high- ly variable even at intraspecific level which makes species difficult to define. As a result, several authors suggested synonymization of all Aponuphis species into one or two species (Bellan, 1964; Kirkegaard, 1988) which, however, has not been corroborated by the most recent 


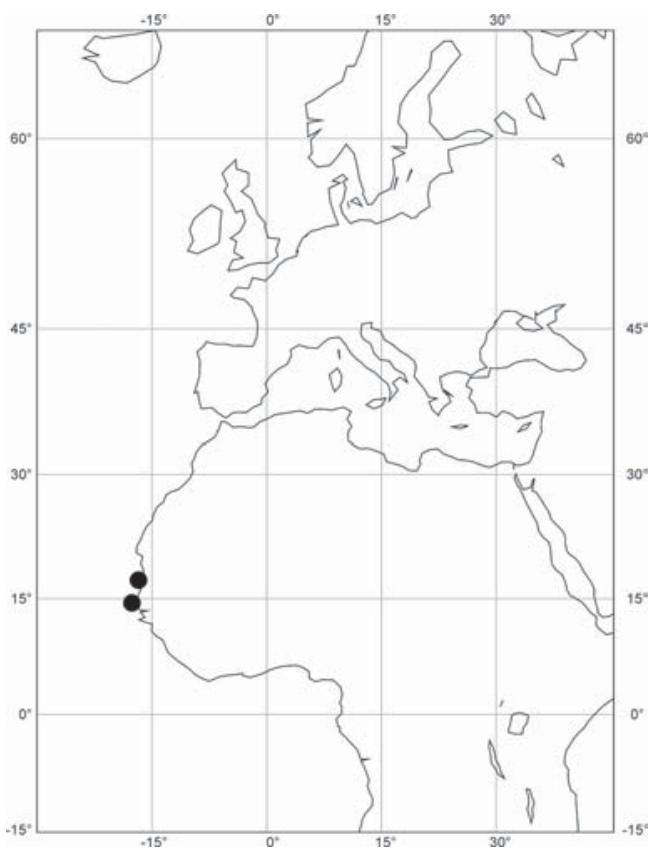

Fig. 11. Distribution of Aponuphis sp. Black circles indicate localities from which genetic data were available.

Рис. 11. Распространение Aponuphis sp. Черными кругами отмечены станции, для которых получены молекулярно-генетические данные.

studies (Arias, Paxton, 2015). On the other hand, Aponuphis is the only genus within onuphids with reported distinct color morphs characteristic for a certain species. Although it has been suggested that color morphs can be used in species identification (Arias, Paxton, 2015), it remained unclear how these morphs correspond with genetic species in Aponuphis.

We have considerably increased the amount of genetic data known for Aponuphis. Until now, the GenBank database contained data on three species. Our results show that the GenBank record for A. bilineata (AY838824) is most probably a misidentification, since this sequence was very divergent form all $\mathrm{A}$. bilinea$t a$ sequences obtained in the present study. This single record was recognized as a provisional species by the ABGD analysis and its taxonomical status remains unresolved. The GenBank record for A. fauveli (KJ027318) clustered within the $A$. brementi species complex confirming the synonymization of these two species proposed by Arias \& Paxton (2015). This specimen fell into clade $\mathrm{E}$ with the peristomium and first chaetiger being darkly pigmented. Aponuphis sp. (KJ027319) from off the Mediterranean French coast also clustered within the $A$. brementi species complex within clade $\mathrm{F}$ with a wide geographical distribution. The color pattern of this specimen is unknown.

Genetic distances between the subclades within the two proposed species complexes ( $A$. bilineata species complex and $A$. brementi species complex) were considerably smaller (3.9$5.4 \%$ and $5.2-9.3 \%$ respectively) than those between the Diopatra species reported by Pires et al. (2010) but were similar or even higher than the genetic distances between the Onuphis species included in the present study (2.1-26.9\%). The ABGD analysis suggested that each of the subclades within the $A$. bilineata and $A$. brementi species complexes should be treated as a separate species. We did not find clear morphological differences between the specimens from different subclades and thus do not formally describe them as species in the present study. Nevertheless, our results indicate the presence of genetic diversity within $A$. bilineata and $A$. brementi that should be investigated further based on examination of additional material and genetic markers.

Aponuphis sp. (clade G) was recognized by the ABGD analysis as a separate species. We only had two specimens of this presumably new species and thus do not describe it as a new species. Aponuphis sp. does not have a distinct color pattern but resembles one of the color morphs of $A$. brementi. However, it occurs much deeper than other species (about $500 \mathrm{~m}$ deep) and has branchiae starting from chaetiger 5 unlike $A$. brementi with branchiae appearing on chaetiger 1-2.

In general, we suggest that color pattern cannot be used as a single diagnostic character in Aponuphis species identification. The presence of typical coloration such as two longitudinal stripes in A. bilineata, paired large dorsal spots in $A$. brementi and the "horse-shoe" pat- 
tern in $A$. ornata allows identification of a species with confidence. However, specimens with less prominent coloration, usually seen as somewhat darker pigmented peristomium and transversal brownish bands on anterior chaetigers, may belong to a range of different species.

Geographical ranges of several Aponuphis species have been extended in the present study. Arias and Paxton (2015) reported A. bilineata from the eastern Atlantic and Mediterranean. We have found this species complex much further to the north in the North Sea and also down to the south off, Morocco, Western Sahara and Guinea. In addition, ten specimens with typical bilineate pattern were reported from São Tomé and Príncipe. The geographical range of $A$. brementi in the eastern Atlantic and Mediterranean (Arias, Paxton, 2015) is here extended to the African coast down to Gabon confirming the synonymization of $A$. fauvel $i$ with its subspecies A. fauveli africana reported from Morocco to Gabon with $A$. brementi. In fact, the color pattern of $A$. fauveli africana resembles the color pattern of $A$. brementi from clade $\mathrm{E}$ in the present study and examination of more material may lead to the resurrection of the subspecies $A$. fauveli africana and elevation to the status of full species with darkly pigmented peristomium and chaetiger 1 . The geographical range of $A$. ornata originally described from Morocco (Fauvel, 1928) and later reported from the Bay of Biscay, Atlantic Iberia and Mediterranean (Arias, Paxton, 2015) remained unchanged.

Currently Aponuphis comprises ten valid species known from the Northern and Eastern Atlantic and eastern Australia. Our findings suggest that the genetic diversity within the genus may be considerably higher than it was accepted before. Each of the three provisional species within $A$. bilineata and A. brementi species complexes may represent a new species. In addition, the deep-water Aponuphis sp. form Senegal and Mauritania as well as erroneously identified A. bilineata from Malta (Struck et al., 2006) may also represent new species. Undoubtedly further investigations involving testing of nuclear genetic markers and morphological variation in Aponuphis species is required.

\section{Acknowledgements}

The authors thank Canary Current Large Marine Ecosystem (CCLME), Guinea Current Large Marine Ecosystem (GCLME) and the Norad funded EAF-Nansen program www.eafnansen.org for access to material. We are grateful to the University Museum of Bergen for supporting the visit of $\mathrm{PB}$ to the Museum with funding granted by the JRS Biodiversity Foundation to the project «Marine Invertebrates of West Africa» Life program. We would like to thank Irina Ekimova for help with molecular lab work. We are also grateful to Egil Severin Erichsen, Irene Heggstad and Katrine Kongshavn for assistance with SEM. Participation of NB in this study was supported by a Marie Curie International Incoming Fellowship (Project PRODEEP) and the Research Council of Norway (top-up financing of Marie Curie Fellows).

\section{References}

Aguirrezabalaga F., Ceberio A., Paxton H. 2002. Onuphidae (Polychaeta) from the Capbreton Canyon (Bay of Biscay, NE Atlantic) with the description of Paradiopatra capbretonensis sp. nov. // Steenstrupia. Vol.27. No.1. P.19-28.

Amoureux L. 1977. Annélides polychètes errantes recueillies sur les pentes du talus continental à l'entrée de la Manche, avec la description de deux espèces nouvelles. Campagne 1973 de la "Thalassa" // Cahiers de Biologie Marine. Vol.18. No.4. P.391-411.

Arias A., Paxton H. 2015. Onuphis and Aponuphis (Annelida: Onuphidae) from southwestern Europe, with the description of a new species // Zootaxa. Vol.3949. No.3. P.345-369.

Augener H. 1918. Polychaeta // Beitrage zur Kenntnis der Meeresfauna Westafrikas. Vol.2. No.2. P.67-625.

Baird W. 1870. Remarks on several genera of annelids belonging to the group Eunicea with a notice of such species as are contained in the collection of the British Museum and a description of some others hitherto undescribed // Journal of the Linnean Society of London. Vol.10. P.341-361.

Bellan G. 1960. Annélides polychètes. Résultats Scientifiques de la Campagne du N.R.P. "Faial" dans les eaux côtières du Portugal // Lisboa. Vol.2. P.1-31.

Bellan G. 1964. Contribution à l'étude systématique, bionomique et écologique des annélides polychètes de la Méditerranée. Thèse, Faculté des Sciences de l'Université d'Aix-Marseille. 371 p.

Budaeva N., Schepetov D., Zanol J., Neretina T., Willassen E. 2016. When molecules support morphology: Phylogenetic reconstruction of the family Onuphidae 
(Eunicida, Annelida) based on 16S rDNA and 18S rDNA // Molecular phylogenetics and evolution. Vol.94. P.791-801.

Detinova N.N. 1985. [Polychaetous annelids of Rejkjanes Ridge (North Atlantic)] // Trudy Instituta Okeanologii PP Shirshova. T.120. P. 96-136 [in Russian].

Diepenbroek M., Grobe H., Sieger R. 2000. PanMap. http://www.pangaea.de/Software/PanMap

Edgar R. C. 2004. MUSCLE: multiple sequence alignment with high accuracy and high throughput // Nucleic acids research. Vol.32. No.5. P.1792-1797.

Fauvel P. 1916. Deux polychètes nouvelles (Disoma watsoni $\mathrm{n}$. sp., et Hyalinoecia brementi n. sp.) // Bulletin d'Institut Oceanographique (Monaco). Vol.316. P.110.

Fauvel P. 1923. Faune de France: Polychètes errantes. Paris: Paul Lechevalier. 488 p.

Fauvel P. 1928. Annélides Polychètes nouvelles du Maroc // Bulletin de la Société Zoologique de France. Vol.53. P.9-13.

Fauvel P. 1936. Contribution à la faune des Annélides Polychètes du Maroc // Mémoires de la Société des Sciences Naturelles du Maroc. Vol.43. P.1-143.

Hektoen M., Budaeva N. 2016. Diversity and phylogeny of Diopatra bristle worms (Onuphidae, Annelida) from West Africa // $12^{\text {th }}$ International Polychaete Conference. National Museum Wales, Cardiff, 01-05 August 2016. Abstract. P.27.

Intes A., Le Loeuff P. 1975. Les annelides polychetes de Cote d'lvoire. I.-Polychetes errantes-compte rendu systematique // Cahiers de la Office de la Recherche Scientifique et Technique des outre mer (Oceanographie). Vol.13. No.4. P.267-321.

Kirkegaard J. B. 1988. The polychaeta of West Africa. Part II. Errant species. 2. Nephtyidae to Dorvilleidae // Atlantide Report. Vol.14. P.7-89.

Kucheruk N.V. 1978. [Deep-water Onuphidae (Polychaeta) from the collections of the 16th cruise of the R/V Dmitry Mendeleev (to the generic classification of the family Onuphidae)] // Trudy Instituta Okeanologii AN SSSR. T113. P.88-106 [in Russian].

Kumar S., Stecher G., Tamura K. 2016. MEGA7: Molecular Evolutionary Genetics Analysis version 7.0 for bigger datasets // Molecular Biology and Evolution Vol.33. P.1870-1874.

Langerhans P. 1880. Wurmfauna von Madeira//Zeitschrift für wissenschaftliche Zoologie. Bd.33. S.267-316.
Palumbi S.R., Martin A., Romano S., McMillan WO., Stice L., Grabowski G. 1991. The Simple Fool's Guide to PCR, Version 2 edition. Department of Zoology, University of Hawaii - Honolulu. 46 p.

Paul C., Halanych K.M., Tiedemann R., Bleidorn C. 2010. Molecules reject an opheliid affinity for Travisia (Annelida) // Systematics and Biodiversity. Vol.8. No.4. P.507-512.

Paxton H. 1986. Generic revision and relationships of the family Onuphidae (Annelida: Polychaeta) // Records of the Australian Museum. Vol.38. No1. P.1-74.

Paxton H. 2017. Three new species of Aponuphis (Annelida: Onuphidae) from eastern Australia // Zootaxa. Vol.4344. P.246-260.

Pires A., Paxton H., Quintino V., Rodrigues A.M. 2010. Diopatra (Annelida: Onuphidae) diversity in European waters with the description of Diopatra micrura, new species // Zootaxa. Vol.2395. P.17-33.

Puillandre N., Lambert A., Brouillet S., Achaz G. 2012. ABGD, Automatic Barcode Gap Discovery for primary species delimitation // Molecular Ecology. Vol.21. No.8. P.1864-1877.

Puslednik L., Serb J.M. 2008. Molecular phylogenetics of the Pectinidae (Mollusca: Bivalvia) and effect of increased taxon sampling and outgroup selection on tree topology // Molecular Phylogenetics and Evolution. Vol.48. P.1178-1188.

Rioja E. 1918. Datos para el conocimiento de la fauna de anélidos poliquetos del Cantábrico ( $2^{\mathrm{a}}$ Parte) // Trabajos del Museo Nacional de Ciencias Naturales, Madrid, Serie Zoológica. Vol.37. P.1-99.

Rullier F. 1965. Contribution à la faune des annélides polychètes du Dahomey et du Togo // Cahiers ORSTOM. Série Océanographie. Vol.3. No.3. P.5-66.

Struck T.H., Purschke G., Halanych K. M. 2006. Phylogeny of Eunicida (Annelida) and exploring data congruence using a partition addition bootstrap alteration (PABA) approach// Systematic Biology. Vol.55. No.1. P. $1-20$.

Zanol J., Halanych K.M., Struck T.H., Fauchald K. 2010. Phylogeny of the bristle worm family Eunicidae (Eunicida, Annelida) and the phylogenetic utility of noncongruent $16 \mathrm{~S}$, COI and $18 \mathrm{~S}$ in combined analyses // Molecular Phylogenetics and Evolution. Vol.55. No.2. P.660-676.

Responsible editor I.A. Jirkov 
Appendix 1. List of stations of RV F. Nansen with materials used in this study.

Приложение 1. Список станций НИС «Ф. Нансен», с которых были получены материалы для данной работы.

\begin{tabular}{|c|c|c|c|c|c|}
\hline Station & Country & Coordinates & Depth, $\mathrm{m}$ & Date & Fixative \\
\hline $5 \mathrm{G}-12$ & Gabon & $\begin{array}{l}\text { S } 2,8702^{\circ} \\
\text { E } 9,4242^{\circ}\end{array}$ & 105 & 08.07 .2005 & $96 \%$ Ethanol \\
\hline $6 \mathrm{~N}-15$ & Nigeria & $\begin{array}{l}\text { N 4,0718 } \\
\text { E 6,6437 }\end{array}$ & 40 & 19.06.2006 & $4 \%$ Formalin \\
\hline $6 \mathrm{~N}-23$ & Nigeria & $\begin{array}{l}\text { N 3,9223 } \\
\text { E 8,1641 }\end{array}$ & 84 & 22.06 .2006 & $96 \%$ Ethanol \\
\hline 7AN-02 & Angola & $\begin{array}{l}\text { S 6,7076 } \\
\text { E } 11,9659^{\circ}\end{array}$ & 106 & 11.07.2007 & $96 \%$ Ethanol \\
\hline 7AN-01 & Angola & $\begin{array}{l}\text { S 7,1452 } \\
\text { E } 12,4721^{\circ}\end{array}$ & 50 & 11.07 .2007 & $96 \%$ Ethanol \\
\hline 7AN-04 & Angola & $\begin{array}{l}\text { S 7,1452 } \\
\text { E } 12,4721^{\circ}\end{array}$ & 65 & 12.07.2007 & $96 \%$ Ethanol \\
\hline $7 \mathrm{BN}-1 \mathrm{E}$ & Benin & $\begin{array}{l}\text { N } 6,0358^{\circ} \\
\text { E } 1,3557^{\circ}\end{array}$ & 44 & 11.06 .2007 & $96 \%$ Ethanol \\
\hline 7GH-1E & Ghana & $\begin{array}{l}\text { N 4,9613 } \\
\text { W 3,0146 }\end{array}$ & 52 & 6.06 .2007 & $?$ \\
\hline 7GH-7D & Ghana & $\begin{array}{l}\text { N 4,5382 } \\
\text { W 2,0449 }\end{array}$ & 76 & 7.06 .2007 & $?$ \\
\hline 7GH-04 & Ghana & $\begin{array}{l}\text { N 4,6427 } \\
\text { W 2,7353 }\end{array}$ & 156 & 6.06 .2007 & $?$ \\
\hline $7 \mathrm{GU}-3 \mathrm{C}$ & Guinea & $\begin{array}{l}\text { N 9,6211 } \\
\text { W 16,1102 }\end{array}$ & 94 & 11.05 .2007 & $4 \%$ Formalin \\
\hline 7SP-03 & $\begin{array}{l}\text { São Tomé } \\
\text { and Príncipe }\end{array}$ & $\begin{array}{l}\text { N 1,6193 } \\
\text { E 7,3364 }\end{array}$ & 47 & 18.06.2007 & $96 \%$ Ethanol \\
\hline 5SP-03 & $\begin{array}{l}\text { São Tomé } \\
\text { and Príncipe }\end{array}$ & $\begin{array}{l}\text { N 1,6361 } \\
\text { E 7,2091 }\end{array}$ & 79 & 26.06 .2005 & $96 \%$ Ethanol \\
\hline $5 \mathrm{C}-11$ & Cameroon & $\begin{array}{l}\text { N 3,2913 } \\
\text { E 9,5675 }\end{array}$ & 37 & 23.06.2005 & $96 \%$ Ethanol \\
\hline E5-7-5B & $\begin{array}{l}\text { São Tomé } \\
\text { and Príncipe }\end{array}$ & $?$ & $?$ & 2008 & $4 \%$ Formalin \\
\hline GR08 & Senegal & $\begin{array}{l}\text { N 14,4596 } \\
\text { W 17,6104 }\end{array}$ & 498 & 05.11 .2011 & $96 \%$ Ethanol \\
\hline
\end{tabular}




\begin{tabular}{|c|c|c|c|c|c|}
\hline Station & Country & Coordinates & Depth, m & Date & Fixative \\
\hline GR11 & Mauritania & 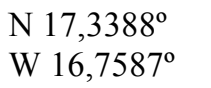 & 518 & 10.11 .2011 & $96 \%$ Ethanol \\
\hline GR28 & W. Sahara & $\begin{array}{l}\text { N } 27,1015^{\circ} \\
\text { W } 13,672^{\circ}\end{array}$ & 125 & 03.12 .2011 & $96 \%$ Ethanol \\
\hline GR37 & Morocco & 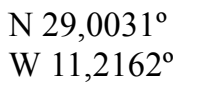 & 106 & 08.12 .2011 & $96 \%$ Ethanol \\
\hline GR40 & Morocco & $\begin{array}{l}\text { N 29,6089 } \\
\text { W 10,2905 }\end{array}$ & 102 & 09.12 .2011 & $96 \%$ Ethanol \\
\hline GR49 & Morocco & $\begin{array}{l}\text { N 32,5418 } \\
\text { W 9,6138 }\end{array}$ & 101 & 11.12 .2011 & $96 \%$ Ethanol \\
\hline GR50 & Morocco & $\begin{array}{l}\mathrm{N} 32,4725^{\circ} \\
\text { W } 9,2744^{\circ}\end{array}$ & 40 & 13.12 .2011 & $96 \%$ Ethanol \\
\hline GR56 & Morocco & $\begin{array}{l}\text { N } 33,6879^{\circ} \\
\text { W } 7,6144^{\circ}\end{array}$ & 55 & 15.12 .2011 & $96 \%$ Ethanol \\
\hline $5 \mathrm{~N}-17$ & Nigeria & $\begin{array}{l}\text { N 3,9435 } \\
\text { E } 8,1848^{\circ}\end{array}$ & 78 & 20.06 .2005 & $96 \%$ Ethanol \\
\hline SL02 & Cape Verde & $\begin{array}{l}\text { N } 15,444^{\circ} \\
\text { W } 23,1366^{\circ}\end{array}$ & 82 & 9.06 .2011 & $96 \%$ Ethanol \\
\hline SL38 & Morocco & $\begin{array}{l}\text { N } 28,0125^{\circ} \\
\text { W } 13,274^{\circ}\end{array}$ & 103 & 29.06 .2012 & $96 \%$ Ethanol \\
\hline GR27 & Morocco & 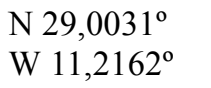 & 106 & 8.12 .2011 & $96 \%$ Ethanol \\
\hline
\end{tabular}

